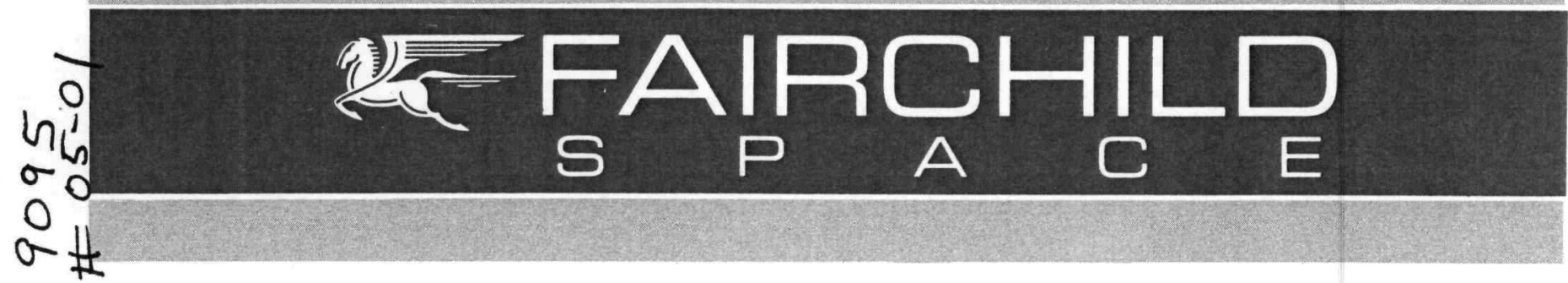

\# y

FSC-ESD-217-94-524

04

$-j$

$\cup$

\title{
Analysis, Optimization, and Assessment of Radioisotope Thermophotovoltaic System Design for an Illustrative Space Mission
}

A. Schock, M. Mukunda, C. Or, and G. Summers

Fairchild Space and Defense Corporation

Germantown, MD 20874 U.S.A

June 28, 1994 


\section{DISCLAIMER}

This report was prepared as an account of work sponsored by an agency of the United States Government. Neither the United States Government nor any agency Thereof, nor any of their employees, makes any warranty, express or implied, or assumes any legal liability or responsibility for the accuracy, completeness, or usefulness of any information, apparatus, product, or process disclosed, or represents that its use would not infringe privately owned rights. Reference herein to any specific commercial product, process, or service by trade name, trademark, manufacturer, or otherwise does not necessarily constitute or imply its endorsement, recommendation, or favoring by the United States Government or any agency thereof. The views and opinions of authors expressed herein do not necessarily state or reflect those of the United States Government or any agency thereof. 


\section{DISCLAIMER}

Portions of this document may be illegible in electronic image products. Images are produced from the best available original document. 


\title{
Analysis, Optimization, and Assessment of Radioisotope Thermophotovoltaic System Design for an Illustrative Space Mission
}

\author{
A. Schock, M. Mukunda, C. Or, and G. Summers \\ Fairchild Space and Defense Corporation \\ Germantown, MD 20874 U.S.A.
}

\begin{abstract}
A companion paper presented at this conference described the design of a Radioisotope Thermophotovoltaic (RTPV) Generator for an illustrative space mission (Pluto Fast Flyby). It presented a detailed design of an integrated system consisting of a radioisotope heat source, a thermophotovoltaic converter, and an optimized heat rejection system. The present paper describes the thermal, electrical, and structural analyses which led to that optimized design, and compares the computed RTPV performance to that of a Radioisotope Thermoelectric Generator (RTG) designed for the same mission.

RTPVs are of course much less mature than RTGs, but our results indicate that when fully developed - they could result in a $60 \%$ reduction of the heat source's mass, cost, and fuel loading, a $50 \%$ reduction of generator mass, a tripling of the power system's specific power, and a quadrupling of its efficiency.

The paper concludes by briefly summarizing the RTPV's current technology status and assessing its potential applicability for the PFF mission. For other power systems (e.g. RTGs), demonstrating their flight readiness for a long mission is a very timeconsuming process to determine the long-term effect of temperature-induced degradation mechanisms. But for the case of the described RTPV design, the paper lists a number of factors, primarily its cold $\left(0\right.$ to $\left.10^{\circ} \mathrm{C}\right)$ converter temperature, that may greatly reduce the need for long-term tests to demonstrate generator lifetime. In any event, our analytical results suggest that the RTPV generator, when developed by DOE and/or NASA, would be quite valuable not only for the Pluto mission but also for other future missions requiring small, long-lived, low-mass generators.
\end{abstract}

\section{INTRODUCTION}

This paper describes the analysis which led to the optimized RTPV design described in the preceding paper [1] and depicted in Figure 1. It summarizes the thermal and electrical analyses of the TPV converter, the static and dynamic structural analyses of the long radiator fins, and the parametric analysis and optimization of the RTPV system. The concluding section compares the RTPV results to those of an RTG designed for the same mission and discusses their programmatic implications. 

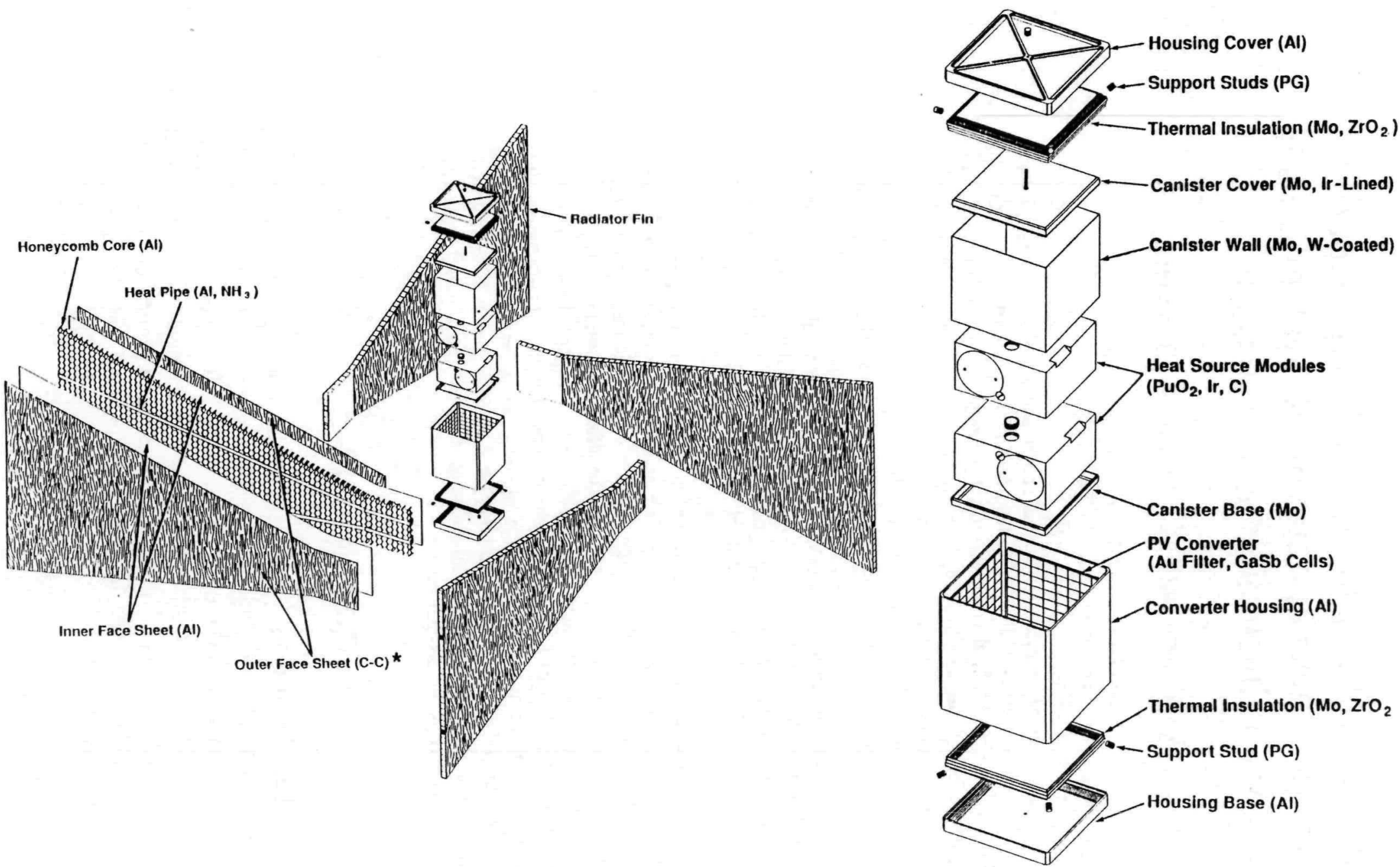

FIGURE 1. Exploded View of RTPV Heat Source, Converter, and Radiator Fins. 


\section{ANALYSIS}

\section{Thermal and Electrical Analysis of TPV Converter}

This subsection presents a generic analysis of the thermophotovoltaic energy conversion process, not tied to any specific converter geometry or heat source thermal power. The equations derived will be applied to specific geometries in subsequent subsections.

The emitted heat flux in the wavelength interval $\lambda$ to $\lambda+d \lambda$ from a black body at absolute temperature $\boldsymbol{T}$ is given by

$$
q(\lambda) d \lambda=\frac{2 \pi h c^{2} \lambda^{-5} d \lambda}{\exp (h c / \lambda k T)-1}
$$

where $\boldsymbol{h}$ and $\boldsymbol{k}$ are Planck's and Boltzmann's constants and $\boldsymbol{c}$ is the speed of light.

For a planar heat source $\boldsymbol{S}$ separated by a vacuum gap from a parallel planar converter $C$, the spectral energy flux leaving each surface is given by the sum of the emitted and reflected radiation:

$$
\begin{aligned}
& q_{s}(\lambda) d \lambda=\varepsilon_{s}(\lambda) \frac{2 \pi h c^{2} \lambda^{-5} d \lambda}{\exp \left(h c / \lambda k T_{s}\right)-1}+R_{s}(\lambda) q_{c}(\lambda) d \lambda, \\
& q_{c}(\lambda) d \lambda=\varepsilon_{c}(\lambda) \frac{2 \pi h c^{2} \lambda^{-5} d \lambda}{\exp \left(h c / \lambda k T_{c}\right)-1}+R_{c}(\lambda) q_{s}(\lambda) d \lambda,
\end{aligned}
$$

where $\varepsilon(\lambda)$ and $R(\lambda)$ are the respective surface's spectral emissivity and reflectivity at wavelength $\lambda$.

The net radiative heat flux $q(\lambda) d \lambda$ emitted by the heat source and absorbed by the converter in the wavelength interval $\lambda$ to $\lambda+d \lambda$ is given by

$$
q(\lambda) d \lambda=\left[q_{s}(\lambda)-q_{c}(\lambda)\right] d \lambda
$$


Solving Eqs. (2) and (3) for $q_{S}(\lambda)$ and $q_{c}(\lambda)$ and inserting the results into Eq. (4), we obtain

$$
q(\lambda) d \lambda=\frac{2 \pi h c^{2} \lambda^{-5}}{1-R_{s}(\lambda) R_{c}(\lambda)}\left[\frac{\varepsilon_{s}(\lambda)\left[1-R_{c}(\lambda)\right]}{\exp \left(h c / \lambda k T_{s}\right)-1}-\frac{\varepsilon_{c}(\lambda)\left[1-R_{s}(\lambda)\right]}{\exp \left(h c / \lambda k T_{c}\right)-1}\right] d \lambda
$$

Since $\boldsymbol{T}_{c} \ll<\boldsymbol{T}_{\boldsymbol{s}}$ in the present case, the second term in the square bracket is negligible, and Eq. (5) reduces to

$$
q(\lambda) d \lambda=\frac{2 \pi h c^{2} \lambda^{-5}}{1-\left[1-\varepsilon_{s}(\lambda)\right] R_{c}(\lambda)}\left[\frac{\varepsilon_{s}(\lambda)\left[1-R_{c}(\lambda)\right]}{\exp \left(h c / \lambda k T_{s}\right)-1}\right] d \lambda,
$$

which can be further reduced to

$$
q(\lambda) d \lambda=\frac{2 \pi h c^{2} \lambda^{-5}\left[\exp \left(h c / \lambda k T_{s}\right)-1\right]^{-1}}{\left[\varepsilon_{s}(\lambda)\right]^{-1}+\left\{\left[R_{c}(\lambda)\right]^{-1}-1\right\}^{-1}} d \lambda .
$$

Note that the converter reflectivity $\boldsymbol{R}_{c}(\lambda)$ includes the effect of the spectrally selective filter, which plays a major role in determining the system efficiency of the generator.

The energy flux absorbed by the converter is in the form of photons. Since each photon has an energy $h v=h c / \lambda$, the absorbed photon flux $\phi_{p}(\lambda) d \lambda$ in the wavelength interval $\lambda$ to $\lambda+d \lambda$ is given by

$$
\phi_{p}(\lambda) d \lambda=\frac{2 \pi \alpha c \lambda^{-4}\left[\exp \left(h c / \lambda k T_{s}\right)-1\right]^{-1}}{\left[\varepsilon_{s}(\lambda)\right]^{-1}+\left\{\left[R_{c}(\lambda)\right]^{-1}-1\right\}^{-1}} d \lambda
$$

where $\alpha$ is the fraction of the converter area covered by active photovoltaic cells. These convert the absorbed photons into an electron flux $\phi_{e}(\lambda) d \lambda$ with a wavelength-dependent quantum efficiency $Q(\lambda)$.

$$
\phi_{e}(\lambda) d \lambda=\phi_{p}(\lambda) Q(\lambda) d \lambda
$$

Thus, the converter's short-circuit current density $\boldsymbol{J}_{\boldsymbol{s} \boldsymbol{c}}$ is given by

$$
J_{s c}=e \int_{0}^{\infty} \phi_{p}(\lambda) Q(\lambda) d \lambda,
$$

where $e$ is the electronic charge. 
Inserting Eqs. (8) and (9) into (10), the short-circuit current density $\boldsymbol{J}_{\boldsymbol{S c}}$ is given by

$$
J_{s c}=2 \pi \alpha c e \int_{0}^{\infty} \frac{\lambda^{-4} Q(\lambda)\left[\exp \left(h c / \lambda k T_{s}\right)-1\right]^{-1}}{\left[\varepsilon_{s}(\lambda)\right]^{-1}+\left\{\left[R_{c}(\lambda)\right]^{-1}-1\right\}^{-1}} d \lambda
$$

The open-circuit voltage $V_{\boldsymbol{O}}$ of each photovoltaic cell is given by

$$
V_{o c}=\left(k T_{c} / e\right) \ln \left[\left(J_{s c} / J_{o}\right)-1\right]
$$

where $\boldsymbol{J}_{\boldsymbol{o}}$ is the saturation current density of the photovoltaic material. According to Boeing investigators, the value of $\boldsymbol{J}_{\boldsymbol{O}}$ is given by

$$
J_{o}=\left[2.555 \times 10^{-4} T_{c}^{3} \exp \left(-E_{g} / k T_{c}\right)\right] \mathrm{amps} / \mathrm{cm}^{2},
$$

where the energy gap $\boldsymbol{E}_{\boldsymbol{g}}$ for gallium antimonide is given by

$$
E_{g}=\left[0.7-3.7 \times 10^{-4}\left(T_{c}-300^{\circ} \mathrm{K}\right)\right] \text { electron volts. }
$$

The short-circuit current density $\boldsymbol{J}_{\boldsymbol{s} \boldsymbol{c}}$ and the open-circuit cell voltage $\boldsymbol{V}_{\boldsymbol{o c}}$ can be used to compute the converter's maximum power output density

$$
P_{\max }=J_{s c} V_{o c} F,
$$

where $\mathbf{F}$ is the fill factor, given by

$$
F=\left\{1-\left[\ln \left(J_{s c} / J_{o}\right)\right]^{-1}\right\}\left\{1-\ln \left[\ln \left(J_{s c} / J_{o}\right)\right]\left[\ln \left(J_{s c} / J_{o}\right)\right]^{-1}\right\} .
$$

In designing the generator, we have assumed that at the maximum power point

$$
\begin{aligned}
& J / J_{s c}=F^{1 / 3}, \\
& V / V_{o c}=F^{2 / 3},
\end{aligned}
$$

which seems to be in good agreement with experimental data.

In applying the above series of equations, we require three sets of experimentally determined data: the heat source emissivity $\varepsilon_{s}(\lambda)$, the converter/filter reflectivity $\boldsymbol{R}_{\boldsymbol{c}}(\lambda)$, and the converter's quantum efficiency $Q(\lambda)$. The first set was obtained from a handbook [2], and the latter two sets were supplied to us by Boeing investigators (E. Horne, M. Morgan). 
TABLE 1. Spectral Transmittance of Filter (AUC-2) and Quantum Efficiency of PV Cell (GaSb)

\begin{tabular}{|c|c|c|c|c|}
\hline \multirow{2}{*}{$\begin{array}{c}\omega \\
\mathrm{cm}^{-1}\end{array}$} & \multicolumn{2}{|c|}{$1-R_{c}(\omega)$} & \multicolumn{2}{|c|}{$\mathbf{Q}(\omega)$} \\
\hline & $M$ & $P$ & $M$ & $P$ \\
\hline 100 & 0.03 & 0.02 & 0.00 & 0.00 \\
\hline 200 & 0.03 & 0.02 & 0.00 & 0.00 \\
\hline 300 & 0.03 & 0.02 & 0.00 & 0.00 \\
\hline 400 & 0.03 & 0.02 & 0.00 & 0.00 \\
\hline 500 & 0.03 & 0.02 & 0.00 & 0.00 \\
\hline 600 & 0.03 & 0.02 & 0.00 & 0.00 \\
\hline 700 & 0.03 & 0.02 & 0.00 & 0.00 \\
\hline 800 & 0.03 & 0.02 & 0.00 & 0.00 \\
\hline 900 & 0.03 & 0.02 & 0.00 & 0.00 \\
\hline 1000 & 0.03 & 0.02 & 0.00 & 0.00 \\
\hline 1100 & 0.03 & 0.02 & 0.00 & 0.00 \\
\hline 1200 & 0.03 & 0.02 & 0.00 & 0.00 \\
\hline 1300 & 0.03 & 0.02 & 0.00 & 0.00 \\
\hline 1400 & 0.03 & 0.02 & 0.00 & 0.00 \\
\hline 1500 & 0.03 & 0.02 & 0.00 & 0.00 \\
\hline 1600 & 0.03 & 0.02 & 0.00 & 0.00 \\
\hline 1700 & 0.03 & 0.02 & 0.00 & 0.00 \\
\hline 1800 & 0.03 & 0.02 & 0.00 & 0.00 \\
\hline 1900 & 0.03 & 0.02 & 0.00 & 0.00 \\
\hline 2000 & 0.03 & 0.02 & 0.00 & 0.00 \\
\hline 2100 & 0.035 & 0.02 & 0.00 & 0.00 \\
\hline 2200 & 0.035 & 0.02 & 0.00 & 0.00 \\
\hline 2300 & 0.035 & 0.02 & 0.00 & 0.00 \\
\hline 2400 & 0.035 & 0.02 & 0.00 & 0.00 \\
\hline 2500 & 0.035 & 0.02 & 0.00 & 0.00 \\
\hline 2600 & 0.035 & 0.02 & 0.00 & 0.00 \\
\hline 2700 & 0.035 & 0.02 & 0.00 & 0.00 \\
\hline 2800 & 0.035 & 0.02 & 0.00 & 0.00 \\
\hline 2900 & 0.04 & 0.02 & 0.00 & 0.00 \\
\hline 3000 & 0.04 & 0.02 & 0.00 & 0.00 \\
\hline 3100 & 0.04 & 0.02 & 0.00 & 0.00 \\
\hline 3200 & 0.04 & 0.02 & 0.00 & 0.00 \\
\hline 3300 & 0.04 & 0.02 & 0.00 & 0.00 \\
\hline 3400 & 0.05 & 0.02 & 0.00 & 0.00 \\
\hline 3500 & 0.05 & 0.02 & 0.00 & 0.00 \\
\hline 3600 & 0.05 & 0.02 & 0.00 & 0.00 \\
\hline 3700 & 0.055 & 0.02 & 0.00 & 0.00 \\
\hline 3800 & 0.055 & 0.02 & 0.00 & 0.00 \\
\hline 3900 & 0.055 & 0.02 & 0.00 & 0.00 \\
\hline 4000 & 0.06 & 0.02 & 0.00 & 0.00 \\
\hline 4100 & 0.06 & 0.02 & 0.00 & 0.00 \\
\hline 4200 & 0.065 & 0.02 & 0.00 & 0.00 \\
\hline 4300 & 0.077 & 0.02 & 0.00 & 0.00 \\
\hline 4400 & 0.08 & 0.02 & 0.00 & 0.00 \\
\hline 4500 & 0.086 & 0.02 & 0.00 & 0.00 \\
\hline 4600 & 0.097 & 0.02 & 0.00 & 0.00 \\
\hline 4700 & 0.1 & 0.02 & 0.00 & 0.00 \\
\hline 4800 & 0.112 & 0.02 & 0.00 & 0.00 \\
\hline 4900 & 0.13 & 0.02 & 0.00 & 0.00 \\
\hline 5000 & 0.14 & 0.02 & 0.00 & 0.00 \\
\hline 5100 & 0.15 & 0.02 & 0.00 & 0.00 \\
\hline 5200 & 0.17 & 0.03 & 0.00 & 0.00 \\
\hline 5300 & 0.183 & 0.04 & 0.00 & 0.00 \\
\hline 5400 & 0.205 & 0.055 & 0.00 & 0.00 \\
\hline
\end{tabular}

\begin{tabular}{|c|c|c|c|c|}
\hline \multirow{2}{*}{$\begin{array}{c}\omega \\
\mathrm{cm}^{-1}\end{array}$} & \multicolumn{2}{|c|}{$1-R_{C}(\omega)$} & \multicolumn{2}{|c|}{$\mathrm{Q}(\omega)$} \\
\hline & $M$ & $P$ & $M$ & $P$ \\
\hline 5500 & 0.023 & 0.08 & 0.10 & 0.11 \\
\hline 5600 & 0.255 & 0.11 & 0.24 & 0.26 \\
\hline 5700 & 0.3 & 0.14 & 0.45 & 0.49 \\
\hline 5800 & 0.325 & 0.16 & 0.55 & 0.60 \\
\hline 5900 & 0.368 & 0.21 & 0.65 & 0.71 \\
\hline 6000 & 0.377 & 0.25 & 0.67 & 0.73 \\
\hline 6100 & 0.411 & 0.3 & 0.71 & 0.78 \\
\hline 6200 & 0.45 & 0.34 & 0.73 & 0.79 \\
\hline 6300 & 0.47 & 0.4 & 0.74 & 0.81 \\
\hline 6400 & 0.49 & 0.47 & 0.75 & 0.82 \\
\hline 6500 & 0.51 & 0.53 & 0.76 & 0.83 \\
\hline 6600 & 0.523 & 0.6 & 0.77 & 0.84 \\
\hline 6700 & 0.532 & 0.665 & 0.78 & 0.85 \\
\hline 6800 & 0.54 & 0.725 & 0.78 & 0.85 \\
\hline 6900 & 0.543 & 0.81 & 0.79 & 0.86 \\
\hline 7000 & 0.54 & 0.83 & 0.79 & 0.85 \\
\hline 7100 & 0.534 & 0.85 & 0.80 & 0.86 \\
\hline 7200 & 0.528 & 0.84 & 0.80 & 0.86 \\
\hline 7300 & 0.51 & 0.835 & 0.81 & 0.87 \\
\hline 7400 & 0.49 & 0.795 & 0.81 & 0.87 \\
\hline 7500 & 0.47 & 0.745 & 0.81 & 0.87 \\
\hline 7600 & 0.443 & 0.695 & 0.81 & 0.87 \\
\hline 7700 & 0.42 & 0.64 & 0.82 & 0.86 \\
\hline 7800 & 0.39 & 0.56 & 0.82 & 0.86 \\
\hline 7900 & 0.365 & 0.48 & 0.82 & 0.85 \\
\hline 8000 & 0.34 & 0.41 & 0.82 & 0.85 \\
\hline 8100 & 0.308 & 0.375 & 0.82 & 0.85 \\
\hline 8200 & 0.28 & 0.35 & 0.82 & 0.85 \\
\hline 8300 & 0.25 & 0.32 & 0.83 & 0.85 \\
\hline 8400 & 0.23 & 0.29 & 0.83 & 0.84 \\
\hline 8500 & 0.208 & 0.275 & 0.83 & 0.84 \\
\hline 8600 & 0.19 & 0.26 & 0.83 & 0.83 \\
\hline 8700 & 0.176 & 0.25 & 0.83 & 0.83 \\
\hline 8800 & 0.158 & 0.24 & 0.82 & 0.83 \\
\hline 8900 & 0.14 & 0.235 & 0.82 & 0.82 \\
\hline 9000 & 0.13 & 0.23 & 0.82 & 0.81 \\
\hline 9100 & 0.118 & 0.225 & 0.82 & 0.81 \\
\hline 9200 & 0.1 & 0.225 & 0.82 & 0.80 \\
\hline 9300 & 0.092 & 0.22 & 0.82 & 0.80 \\
\hline 9400 & 0.08 & 0.22 & 0.82 & 0.78 \\
\hline 9500 & 0.7 & 0.215 & 0.82 & 0.77 \\
\hline 9600 & 0.06 & 0.21 & 0.81 & 0.76 \\
\hline 9700 & 0.055 & 0.205 & 0.80 & 0.75 \\
\hline 9800 & 0.05 & 0.2 & 0.80 & 0.74 \\
\hline 9900 & 0.04 & 0.2 & 0.79 & 0.73 \\
\hline 10000 & 0.035 & 0.195 & 0.78 & 0.71 \\
\hline 10100 & 0.03 & 0.1875 & 0.77 & 0.70 \\
\hline 10200 & 0.025 & 0.18 & 0.76 & 0.69 \\
\hline 10300 & 0.023 & 0.1766 & 0.75 & 0.69 \\
\hline 10400 & 0.021 & 0.1733 & 0.75 & 0.69 \\
\hline 10500 & 0.02 & 0.17 & 0.74 & 0.68 \\
\hline 10600 & 0.02 & 0.1666 & 0.73 & 0.67 \\
\hline 10700 & 0.017 & 0.1633 & 0.72 & 0.66 \\
\hline 10800 & 0.016 & 0.16 & 0.71 & 0.65 \\
\hline
\end{tabular}

\begin{tabular}{|c|c|c|c|c|}
\hline \multirow{2}{*}{$\begin{array}{c}\omega \\
\mathrm{cm}^{-1}\end{array}$} & \multicolumn{2}{|c|}{$1-R_{C}(\omega)$} & \multicolumn{2}{|c|}{$Q(\omega)$} \\
\hline & $M$ & $P$ & $M$ & $P$ \\
\hline 10900 & 0.02 & 0.157 & 0.70 & 0.64 \\
\hline 11000 & 0.02 & 0.156 & 0.70 & 0.64 \\
\hline 11100 & 0.025 & 0.155 & 0.69 & 0.63 \\
\hline 11200 & 0.03 & 0.15 & 0.68 & 0.62 \\
\hline 11300 & 0.035 & 0.15 & 0.67 & 0.61 \\
\hline 11400 & 0.04 & 0.1 & 0.66 & 0.60 \\
\hline 11500 & 0.05 & 0.1 & 0.65 & 0.59 \\
\hline 11600 & 0.052 & 0.1 & 0.64 & 0.58 \\
\hline 11700 & 0.053 & 0.1 & 0.63 & 0.58 \\
\hline 11800 & 0.055 & 0.1 & 0.62 & 0.57 \\
\hline 11900 & 0.056 & 0.1 & 0.61 & 0.56 \\
\hline 12000 & 0.057 & 0.1 & 0.60 & 0.55 \\
\hline 12300 & 0.055 & 0.1 & 0.60 & 0.55 \\
\hline 12600 & 0.05 & 0.1 & 0.58 & 0.53 \\
\hline 12900 & 0.045 & 0.1 & 0.56 & 0.51 \\
\hline 13200 & 0.04 & 0.1 & 0.54 & 0.49 \\
\hline 13500 & 0.04 & 0.1 & 0.52 & 0.49 \\
\hline 13800 & 0.035 & 0.1 & 0.50 & 0.48 \\
\hline 14100 & 0.03 & 0.11 & 0.48 & 0.47 \\
\hline 14400 & 0.05 & 0.1 & 0.46 & 0.46 \\
\hline 14700 & 0.05 & 0.1 & 0.45 & 0.46 \\
\hline 15000 & 0.05 & 0.1 & 0.44 & 0.46 \\
\hline 15300 & 0.05 & 0.1 & 0.43 & 0.46 \\
\hline 15600 & 0.05 & 0.1 & 0.42 & 0.46 \\
\hline 15900 & 0.05 & 0.1 & 0.40 & 0.45 \\
\hline 16200 & 0.05 & 0.1 & 0.38 & 0.45 \\
\hline 16500 & 0.05 & 0.1 & 0.36 & 0.44 \\
\hline 16800 & 0.05 & 0.1 & 0.34 & 0.42 \\
\hline 17100 & 0.05 & 0.1 & 0.32 & 0.40 \\
\hline 17400 & 0.05 & 0.1 & 0.31 & 0.38 \\
\hline 17700 & 0.05 & 0.1 & 0.30 & 0.37 \\
\hline 18000 & 0.05 & 0.1 & 0.30 & 0.37 \\
\hline 18300 & 0.05 & 0.1 & 0.30 & 0.37 \\
\hline 18600 & 0.05 & 0.1 & 0.30 & 0.37 \\
\hline 18900 & 0.05 & 0.1 & 0.32 & 0.40 \\
\hline 19200 & 0.05 & 0.1 & 0.35 & 0.43 \\
\hline 19500 & 0.05 & 0.1 & 0.38 & 0.47 \\
\hline 19800 & 0.05 & 0.1 & 0.40 & 0.50 \\
\hline 20100 & 0.05 & 0.1 & 0.41 & 0.43 \\
\hline 20400 & 0.05 & 0.1 & 0.42 & 0.44 \\
\hline 20700 & 0.05 & 0.1 & 0.43 & 0.45 \\
\hline 21000 & 0.05 & 0.1 & 0.44 & 0.46 \\
\hline 21300 & 0.05 & 0.1 & 0.45 & 0.47 \\
\hline 21600 & 0.05 & 0.1 & 0.46 & 0.48 \\
\hline 21900 & 0.05 & 0.1 & 0.47 & 0.49 \\
\hline 22200 & 0.05 & 0.1 & 0.48 & 0.50 \\
\hline 22500 & 0.05 & 0.1 & 0.50 & 0.53 \\
\hline 22800 & 0.05 & 0.1 & 0.50 & 0.53 \\
\hline 23100 & 0.05 & 0.1 & 0.50 & 0.53 \\
\hline 23400 & 0.05 & 0.1 & 0.48 & 0.50 \\
\hline 23700 & 0.05 & 0.11 & 0.46 & 0.48 \\
\hline 24000 & 0.05 & 0.1 & 0.43 & 0.45 \\
\hline 24300 & 0.05 & 0.1 & 0.40 & 0.42 \\
\hline 24600 & 0.05 & 0.1 & 0.36 & 0.38 \\
\hline 24900 & 0.05 & 0.1 & 0.36 & 0.38 \\
\hline
\end{tabular}

As shown in Table 1, their data is given in terms of the wave number $\omega$, the reciprocal of the wavelength $\lambda$. Therefore, it is convenient to recast Eq. (11) in terms of wave number:

$$
J_{s c}=2 \pi \alpha c e \int_{0}^{\infty} \frac{\omega^{2} Q(\omega)\left[\exp \left(h c \omega / k T_{s}\right)-1\right]^{-1}}{\left[\varepsilon_{s}(\omega)\right]^{-1}+\left\{\left[R_{c}(\omega)\right]^{-1}-1\right\}^{-1}} d \omega .
$$


Two sets of data are listed in Table 1 for the filter's spectral reflectivity $\mathbf{R}_{\mathbf{c}}(\boldsymbol{\omega})$ and the cell's quantum efficiency $Q(\omega)$. For each property, the more conservative measured data set $(M)$ is based on measurements of already fabricated nonoptimized samples made by Boeing investigators for other ap plications, and the "improved" or "projected" data set $(\boldsymbol{P})$ is based on their estimates of what improvements could be achieved by known stratagems for optimizing the filter and the photovoltaic cells for the present RTPV application. The illustrative example described in this section is based on the improved properties set, but later sections that summarize the results of our integrated RTPV system studies present results for both the more conservative measured performance parameters and the predicted improved properties. Our studies showed that the projected improvements in quantum efficiency had only a minor effect on system performance, but that the improved filter characteristics had a pronounced effect.

\section{Illustrative Example}

To illustrate the application of the above-derived equations, consider a heat source enclosed in a smooth tungsten-coated canister with the handbook-given [2] values of spectral emissivity $\boldsymbol{\varepsilon}(\lambda)$ depicted by the solid curve of Figure 2 . The canister operates at an illustrative temperature $T_{s}=1150^{\circ} \mathrm{C}=1423^{\circ} \mathrm{K}$, and radiates to a spectral filter and gallium antimonide photovoltaic cells at a converter temperature of $\boldsymbol{T}_{\boldsymbol{c}}=0^{\circ} \mathrm{C}=273^{\circ} \mathrm{K}$ with an active area fraction $\boldsymbol{\alpha}=0.90$.

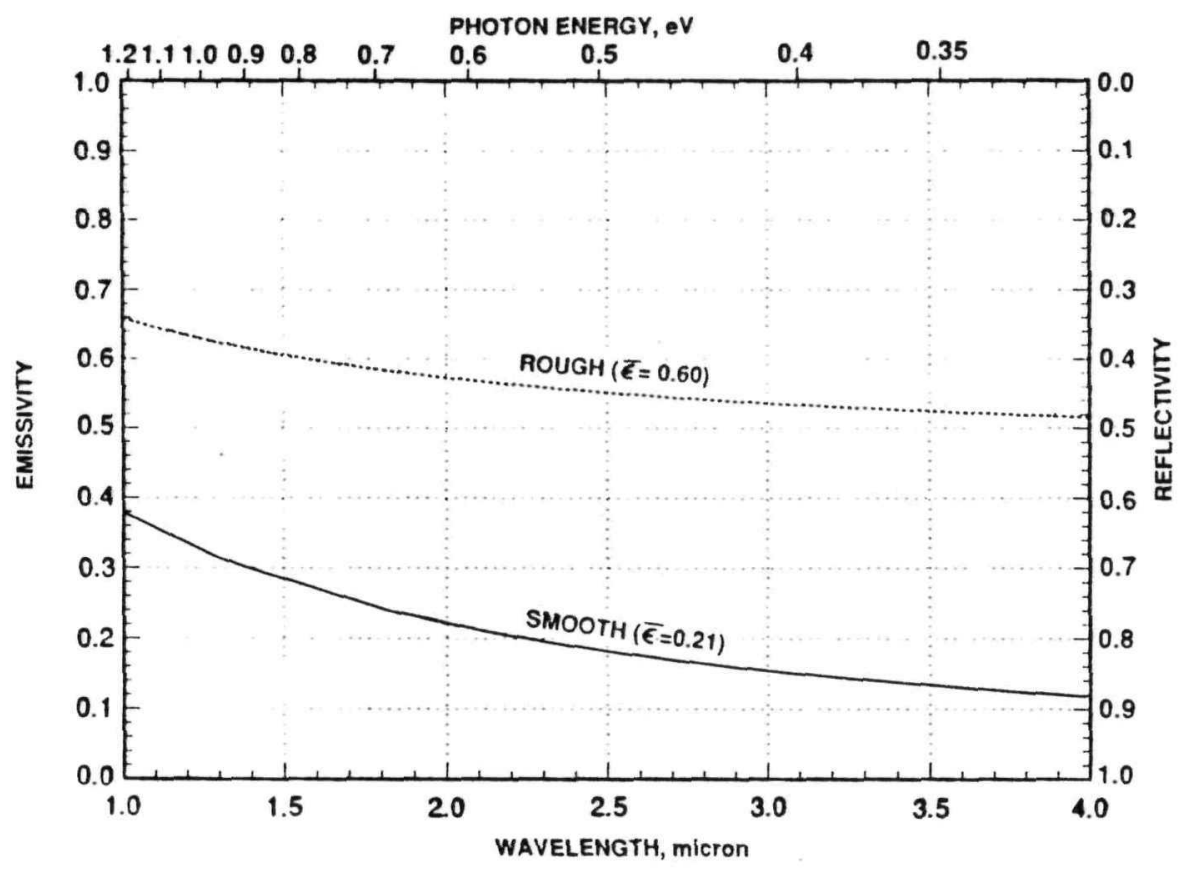

FIGURE 2. Spectral Emissivity of Tungsten Canister. 
(There was no Page 8 in original document.) 


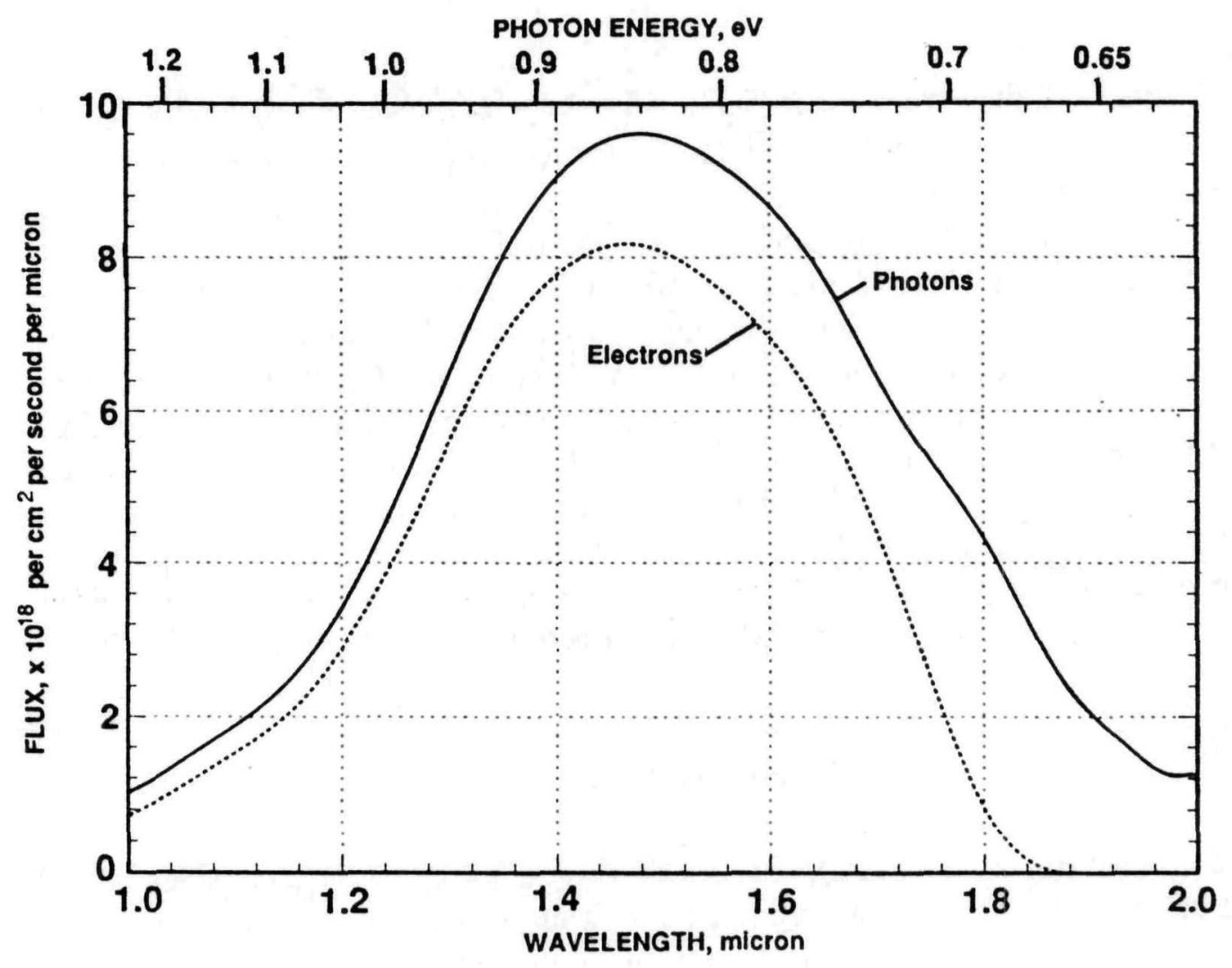

FIGURE 4. Illustrative Example Absorbed Photon Flux and Generated Electron Flux Spectra.

Applying numerical integration over the range of wavelengths to the illustrative example:

Eq. (9) gives the net heat flux absorbed by the converter $q_{\text {net }}=0.99 \mathrm{watt} / \mathrm{cm}^{2}$,

Eq. (11) gives the short-circuit current density $J_{s c}=0.62 \mathrm{amp} / \mathrm{cm}^{2}$,

Eqs. $(12,13,14)$ give the open-circuit voltage $V_{O C}=0.50$ volt,

Eq. (16) gives the fill factor $F=0.82$,

Eq. (15) gives the maximum power density of the converter $P_{\max }=0.25$ watt $/ \mathrm{cm}^{2}$,

Eqs. (17) and (18) give the current density $J=0.58 \mathrm{amp} / \mathrm{cm}^{2}$ and cell voltage $\mathrm{V}=0.44$ volt,

and the corresponding converter efficiency is $\eta=P_{\text {max }} / q_{\text {net }}=25.2 \%$. 
Similar numerical integrations were carried out for a range of heat source temperatures $\boldsymbol{T}_{\boldsymbol{s}}$ and converter temperatures $\boldsymbol{T}_{\boldsymbol{c}}$, with the parametric results displayed in Figures 5 through 8. Figure 5 shows that the net heat flux is only a function of the source temperature, and is essentially independent of the cell temperature in the range of interest.

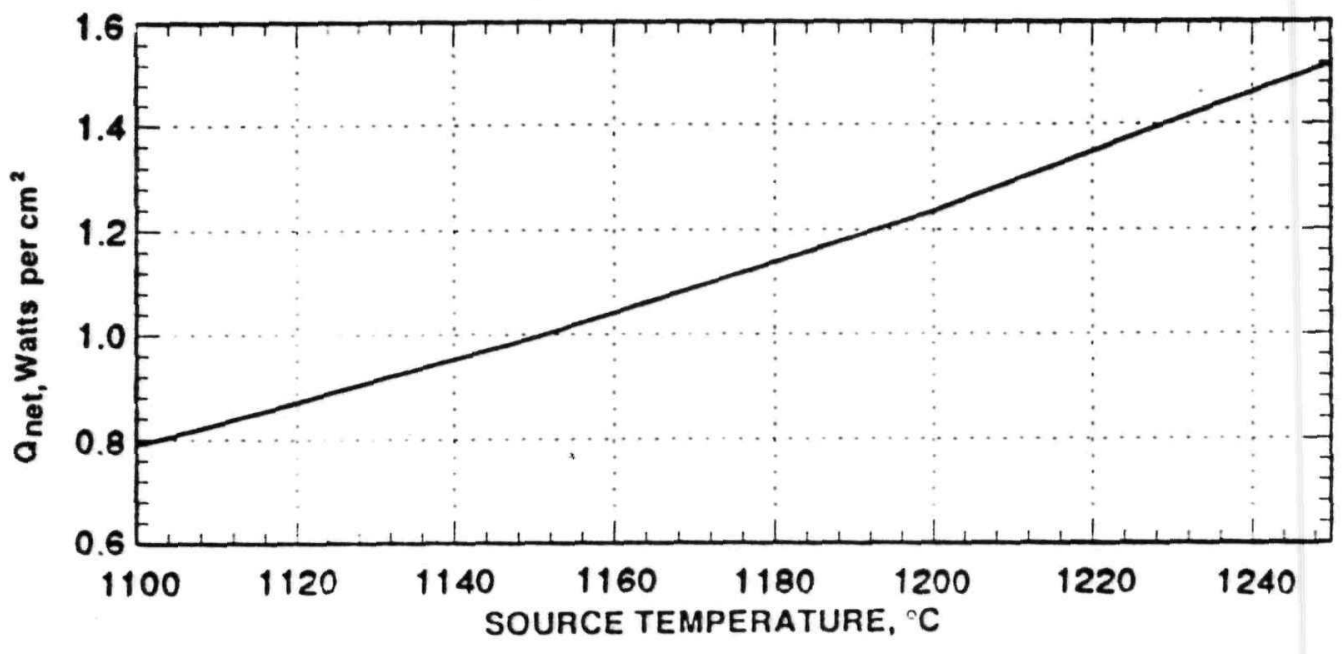

FIGURE 5. Effect of Source Temperature on Net Heat Flux Absorbed by Converter.

Figures 6 and 7 show that the output power density and the converter efficiency are sensitive functions of the cell temperature. Lowering that temperature leads to significant performance improvements, albeit at the cost of increased radiator mass. Trade-offs between those parameters to maximize the system's specific power are described in a later section.

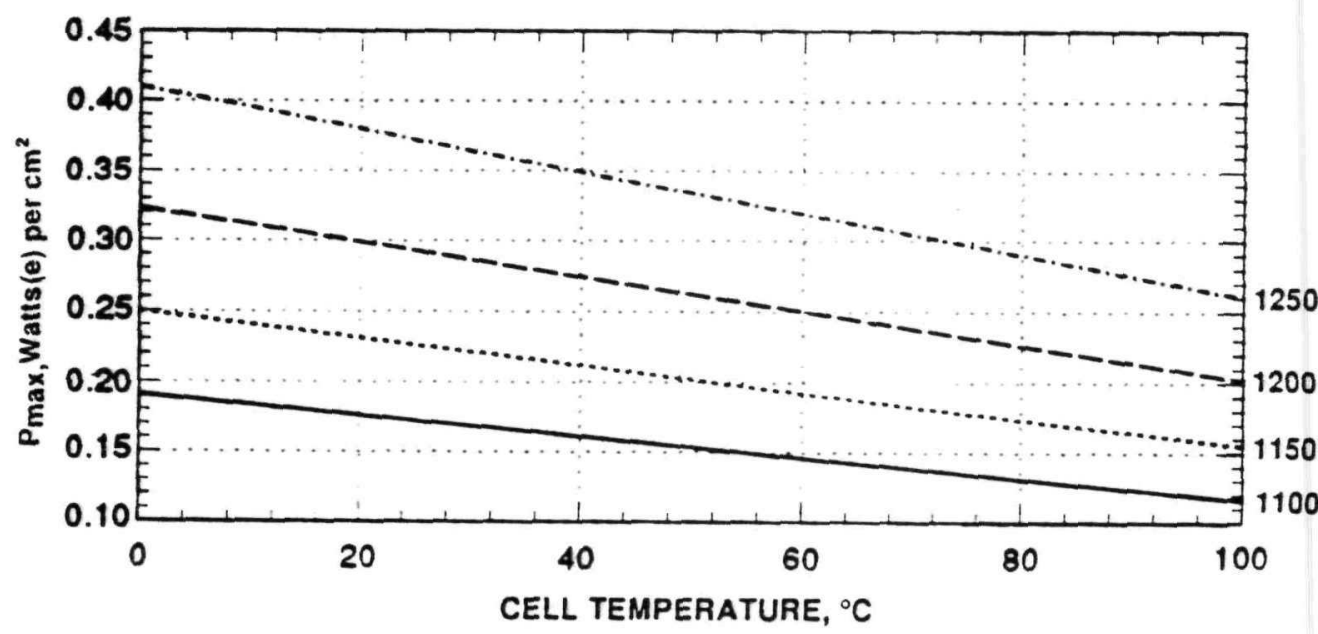

FIGURE 6. Effect of Source and Cell Temperatures on Maximum Power Density of Converter. 


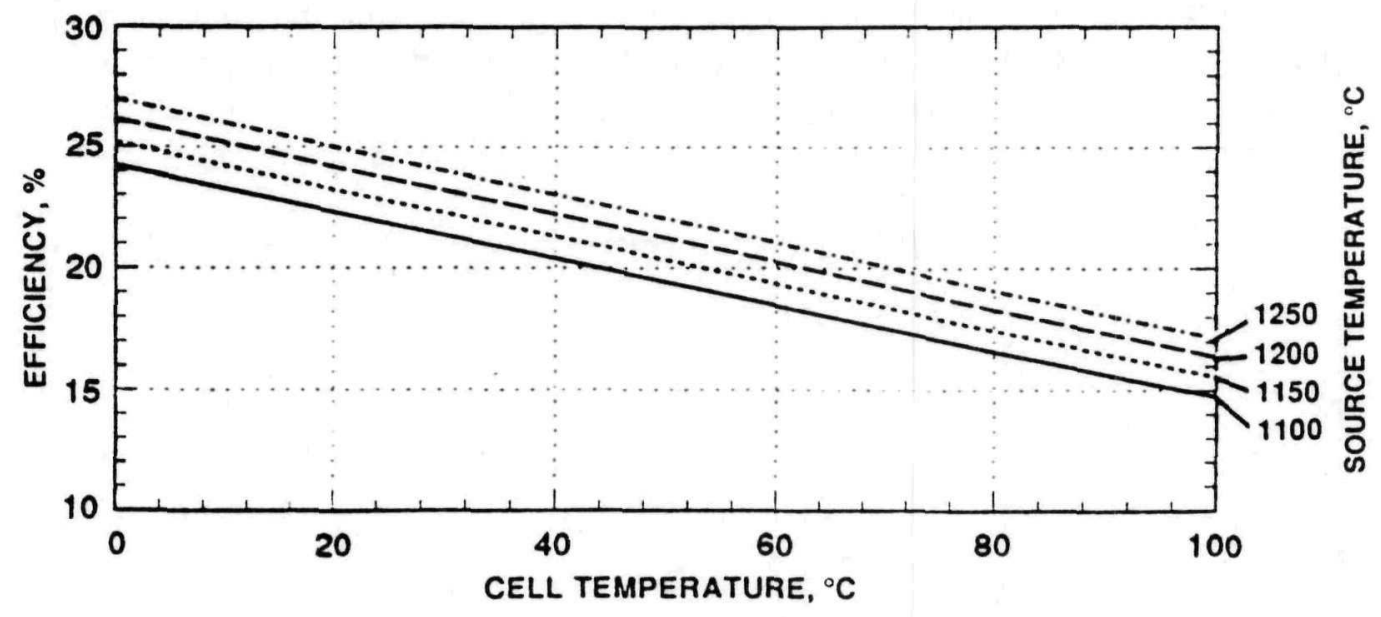

FIGURE 7. Effect of Source and Cell Temperatures on Converter Efficiency.

The results of Figures 5, 6, and 7 are combined in Figure 8, which presents cross-plots showing the effect of $q_{\text {net }}$ on $\boldsymbol{T}_{\boldsymbol{s}}, \boldsymbol{P}_{\max }$, and $\boldsymbol{\eta}$, for a range of cell temperatures $T_{c}$. It again shows the performance improvement obtainable by lowering the cell temperature.

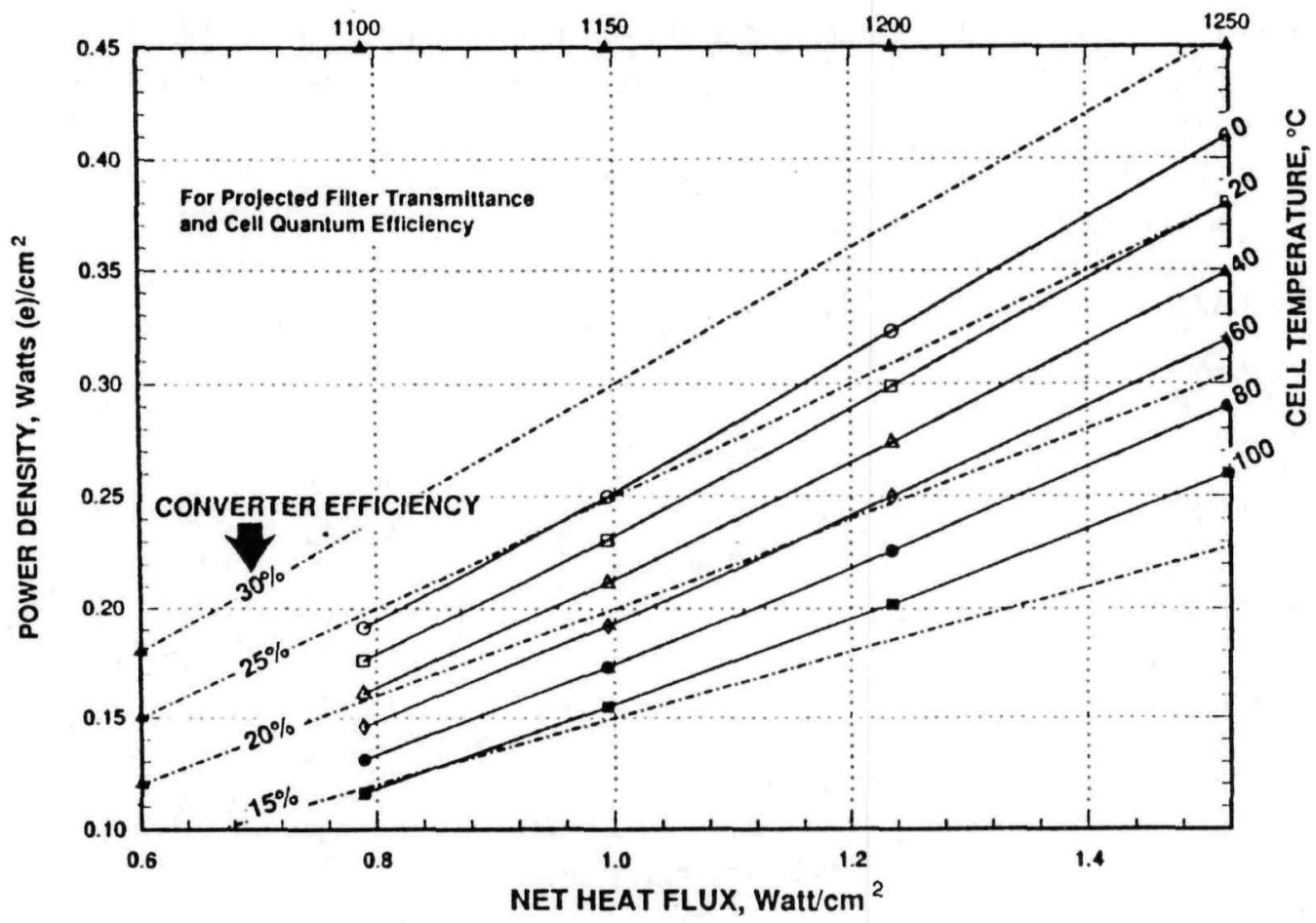

FIGURE 8. Effect of Net Heat Flux and Cell Temperature on Source Temperature, Power Density, and Efficiency. 
Figure 8 also shows that, for a given heat flux, higher source temperatures lead to higher power densities and efficiencies. From that, one might infer that these parameters can be significantly increased by lowering the heat source emissivity, which raises the source temperature for a given heat flux. But quite the opposite was found to be the case. This was discovered in the Fairchild study when the effect of roughening the tungsten surface on the converser's performance was analyzed.

The effective total emissivity, $\overline{\varepsilon_{s}}$ of the heat source canister is obtained by a weighted average of its spectral emissivity $\varepsilon_{s}(\lambda)$ :

$$
\overline{\varepsilon_{s}}=\frac{\int_{0}^{\infty} \lambda^{-5}\left[\exp \left(h c / \lambda k T_{s}\right)-1\right]^{-1} \varepsilon_{s}(\lambda) d \lambda}{\int_{0}^{\infty} \lambda^{-5}\left[\exp \left(h c / \lambda k T_{s}\right)-1\right]^{-1} d \lambda}
$$

Applying the spectral emissivities for smooth tungsten shown by the solid curve in Figure 2 gives a value of 0.21 for $\bar{\varepsilon}_{s}$. It was assumed that roughening the tungsten (e.g., by grit blasting) would raise its effective total emissivity to 0.60 . This corresponds to a $45 \%$ reduction of the smooth-tungsten spectral reflectivity $\left[1-\varepsilon_{\mathrm{S}}(\lambda)\right]$, resulting in the spectral emissivity for roughened tungsten shown by the dashed curve of Figure 2.

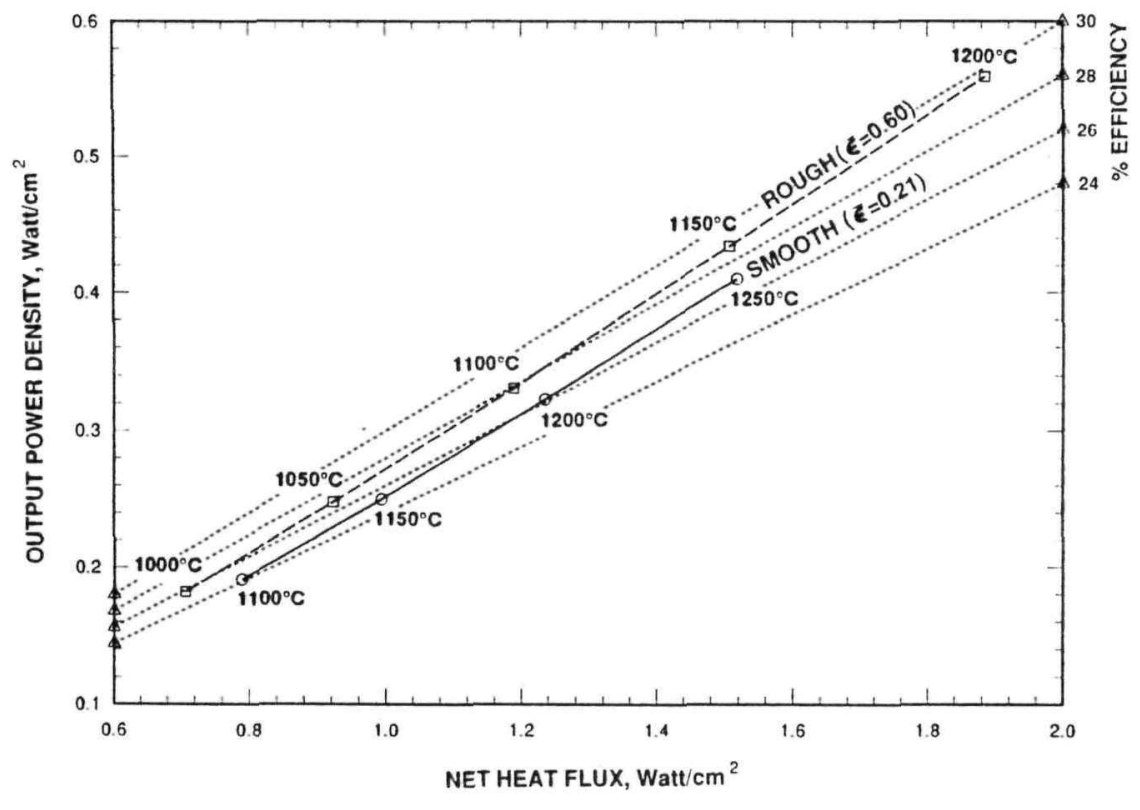

FIGURE 9. Effect of Canister Roughness on its Temperature, Converter Efficiency, and Output Power. 
The effect of that emissivity increase is shown in Figure 9, which compares the converter's computed performance for smooth and roughened canisters at a $0^{\circ} \mathrm{C}$ cell temperature. As can be seen, for the same heat flux the roughened canister actually yields a somewhat higher power density and converter efficiency, contrary to expectations. Most important, it does so at an appreciably lower heat source temperature (by almost $100^{\circ} \mathrm{C}$ ). Since lowering the heat source temperature without loss of performance is a desirable goal, the balance of our RTPV design study assumed the use of a roughened tungsten canister.

\section{System Analysis}

Determining the optimum system design, particularly the fin design that maximizes the system's specific power, requires a coupled thermal and electrical analysis. In that analysis, the heat generation rate is known, but the heat source surface temperature $T_{s}$ and cell temperature $T_{c}$ are not. Therefore, the analysis must be carried out iteratively. The coupled analysis was carried out by means of a thermal analysis code (SINDA [3]) that had been modified by Fairchild, and by a standard thermal radiation code (SSPTA [4]). For the former we constructed a 197-node model, and for the latter a model consisting of 496 surfaces.

Fairchild made two major modifications in the thermal analysis code. The net heat flux $\boldsymbol{q}_{\boldsymbol{n} \text { et }}$ from the sides of the heat source to the converter cells at each iteration was computed by integration of Eq. (7),

$$
q_{n e t}=2 \pi h c^{2} \int_{o}^{\infty} \frac{\lambda^{-5}\left[\exp \left(h c / \lambda k T_{s}\right)-1\right]^{-1}}{\left[\varepsilon_{s}(\lambda)\right]^{-1}+\left\{\left[R_{c}(\lambda)\right]^{-1}-1\right\}^{-1}} d \lambda,
$$

with appropriate corrections for gaps between cells and obstruction by the electrical grid; and the waste heat flowing to the radiator fins was computed by subtracting the converter's electrical power generation rate from the heat generation rate of the heat source. The power generation rate was computed by multiplying the total cell area of the generator by the power density $\boldsymbol{P}_{\max }$ obtained from Eqs. (11) through (16). The two thermal codes computed a new set of canister and cell temperatures, which were used as inputs in the next iteration. This iterative procedure was repeated until the modified code converged on a consistent solution.

\section{Structural Analysis}

Before applying the above procedure to optimize the system design, we must first perform a static and dynamic structural analysis of the radiator to ensure that 
the long fins required for the desired low cell temperatures can survive the predicted launch loads without excessive stresses in their aluminum skins. In our structural analysis we assumed that the graphite skin contributes zero strength in the direction normal to the fibers.

Consider a fin of root-to-tip length $x_{1}$, honeycomb thickness $z_{o}$, and height $y$ varying from $y_{o}$ at the fin tip to $y_{1}$ at the fin root. Let $x$ denote the horizontal distance from the fin tip. Then the fin height $y$ at position $\boldsymbol{x}$ is given by

$$
y=y_{o}-x\left(y_{o}-y_{1}\right) / x_{1}=y_{o}-y^{\prime} x,
$$

where $y^{\prime}$ is defined as $\left(y_{0}-y_{1}\right) / x_{1}$. The total mass $d \boldsymbol{m}$ of the fin segment between $x$ and $\boldsymbol{x}+\boldsymbol{d x}$ is given by

$$
d m=\left[2 m_{1}+m_{2} y+2 m_{3} y t_{o}\right] d x,
$$

where $\boldsymbol{m}_{\boldsymbol{1}}$ is the mass per unit length of each heat pipe, $\boldsymbol{m}_{\boldsymbol{2}}$ is the mass per unit area of the honeycomb plus that of the two graphite skins and of the bond between them, $\boldsymbol{m}_{\mathbf{3}}$ is the volumetric density of the aluminum skins, and $\boldsymbol{t}_{\boldsymbol{o}}$ is the thickness of each aluminum skin. Combining Eqs. (22) and (23), we obtain

$$
d m=\left[2 m_{1}+\left(m_{2}+2 m_{3} t_{o}\right)\left(y_{o}-y^{\prime} x\right)\right] d x .
$$

When the fin is subjected to an acceleration load of magnitude $g$ normal to its surface, the resultant bending moment $\boldsymbol{M}$ at position $\boldsymbol{x}$ is given by

$$
M=g \int_{0}^{x}\left(x-x^{\prime}\right)\left[2 m_{1}+\left(m_{2}+2 m_{3} t_{o}\right)\left(y_{o}-y^{\prime} x^{\prime}\right)\right] d x^{\prime},
$$

where $x^{\prime}$ is the variable of integration. Integrating Eq. (24) from $x^{\prime}=0$ to $x^{\prime}=x$, we obtain

$$
M=g\left[m_{1} x^{2}+\left(m_{2}+2 m_{3} t_{o}\right)\left(1 / 2 y_{o} x^{2}-1 / 6 y^{\prime} x^{3}\right)\right]
$$

The maximum tensile stress $\boldsymbol{\sigma}$ in the aluminum fin at position $\boldsymbol{x}$ is given by

$$
\sigma=(1 / 2 z) M / I
$$

where $\boldsymbol{I}$, the combined moment of inertia of the aluminum skins and the heat pipes at position $\boldsymbol{x}$, is given by

$$
I=\frac{1}{12} y\left[\left(z+2 t_{o}\right)^{3}-z^{3}\right]+2 I_{o}
$$

and $I_{\boldsymbol{o}}$, the moment of inertia of each rectangular heat pipe of base width $\boldsymbol{b}$, depth $z$, and wall thickness $w$, is given by 


$$
I_{o}=\frac{1}{12}\left[b z^{3}-(b-2 w)(z-2 w)^{3}\right] .
$$

Since the aluminum skin thickness $\boldsymbol{t}_{\boldsymbol{o}}$ is much smaller than the honeycomb thickness $z$, Eq. (28) reduces to

$$
I=\frac{1}{2} y z^{2} t_{o}+2 I_{o} .
$$

Inserting Eqs. (26) and (30) into (27), the maximum tensile stress $\sigma$ at position $x$ is given by

$$
\sigma=\frac{g\left[\left(m_{1}+1 / 2 m_{2} y_{o}+m_{3} y_{o} t_{o}\right) x^{2}-1 / 6\left(m_{2}+2 m_{3} t_{o}\right) y^{\prime} x^{3}\right]}{\left(y_{o}-y^{\prime} x\right) z t_{o}+4 I_{o} / z} .
$$

Figure 10 shows illustrative stress profiles in the aluminum skins when a fin with the indicated dimensions and component mass densities is subjected to quasistatic acceleration of $40 \mathrm{~g}$ or $392 \mathrm{~m} / \mathrm{s}^{2}$ normal to its surface. This g-level was selected because that is the level to which previous RTGs [5] were designed and qualification-tested. But $40 \mathrm{~g}$ is quite conservative for the present application, because the RTPV under study is much shorter than the RTGs, and because a quasi-static load may inherently be an overconservative representation of the dynamic launch loads. The figure presents stress profiles computed from Eq. (31) for aluminum skin thicknesses $\boldsymbol{t}_{\boldsymbol{o}}$ ranging from $0.003^{\prime \prime}$ to $0.010^{\prime \prime}$. As can be seen, decreasing the skin thickness increases the stress, but not very much because the effect of the smaller cross-sectional area is largely compensated by the reduced fin weight.

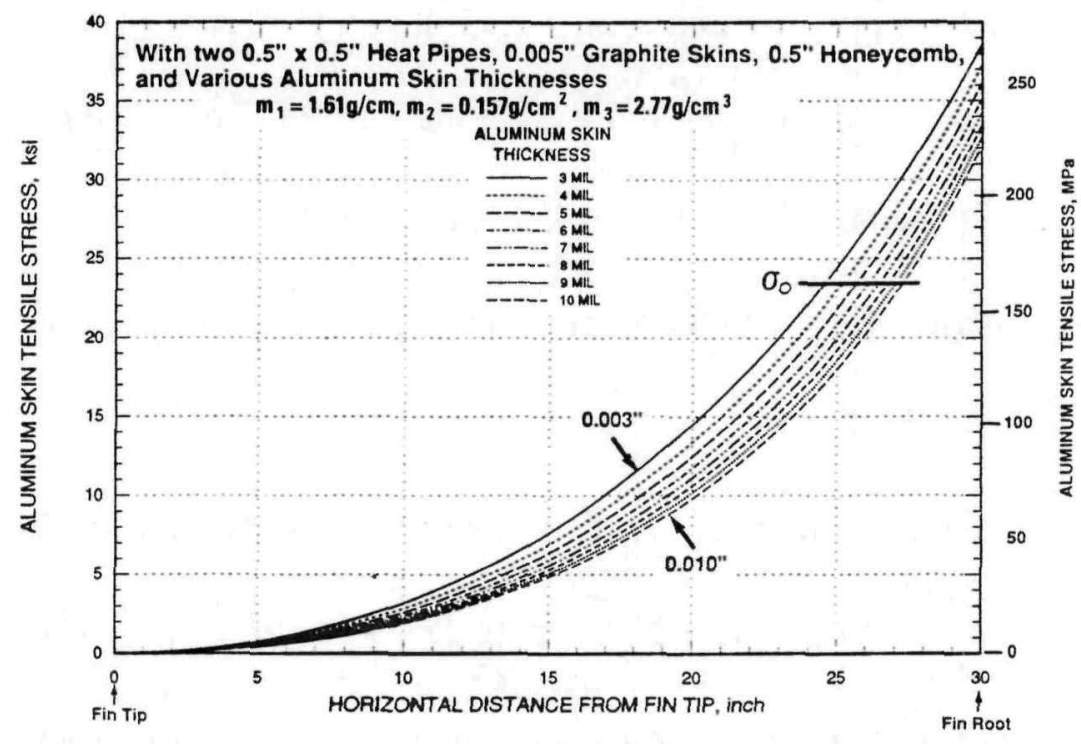

FIGURE 10. Tensile Stress Profile Produced by 40-G Side Load on Fin with 20" Tip Height, 4.7" Base Height. 
In Figure $10, \boldsymbol{\sigma}_{\boldsymbol{o}}$ denotes the maximum allowable tensile stress in the aluminum alloy. For a yield stress of $241 \mathrm{MPa}(35 \mathrm{ksi})$, a safety factor of 1.5 gives an allowable stress of $159 \mathrm{MPa}$ (23 ksi). As can be seen, over most of the fin length the computed maximum stress displayed is less than the allowable stress. Even for the thinnest aluminum skin $(0.003 ")$ this is true for 24 " of the 30 " fin length. But near the fin root, the skin stress exceeds the allowable limit. To avoid this, the skin thickness must be gradually increased near the fin root, as illustrated in Figure 11 for skin thicknesses at the fin tip ranging from 0.003 " to $0.010^{\prime \prime}$.

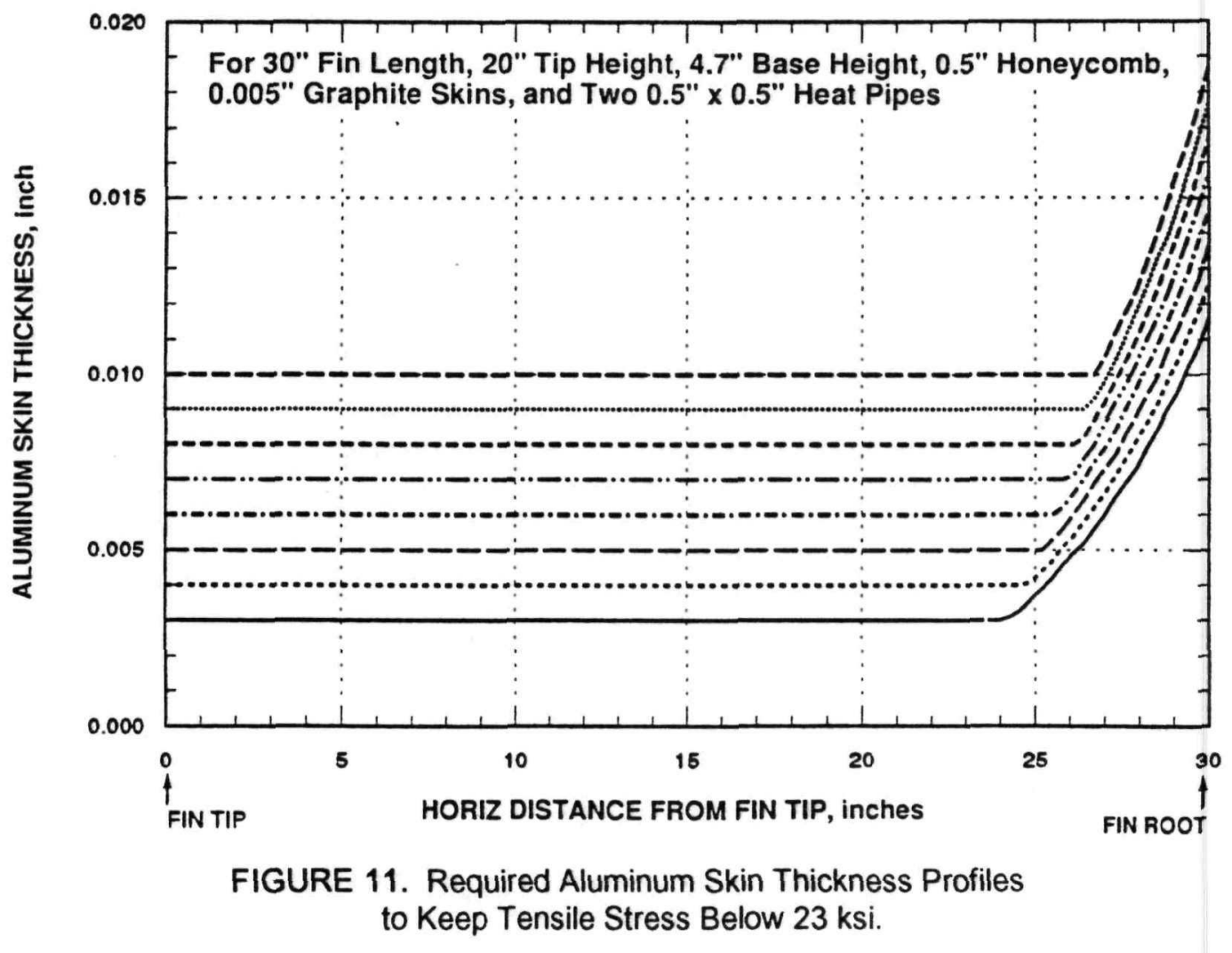

The figure shows that reducing the initial skin thickness will lighten the radiator even when the required skin thickening near the fin root is taken into account. Therefore, in our design study the aluminum skin thickness, except near the fin root, was fixed at $0.003 "$, which was deemed the minimum practical thickness.

Figure 12 shows the required aluminum skin thickness at the fin root, for fin lengths ranging from $20^{\prime \prime}$ to $40^{\prime \prime}$, honeycomb thicknesses of $0.38^{\prime \prime}$ and $0.50^{\prime \prime}$, and skin thicknesses of 3 to 6 mils at the fin tips.

The figure shows that increasing the honeycomb thickness reduces the required skin thickness, as would be expected. However, the skin mass reduction must be traded off against the honeycomb mass increase, as illustrated in Figure 13. 


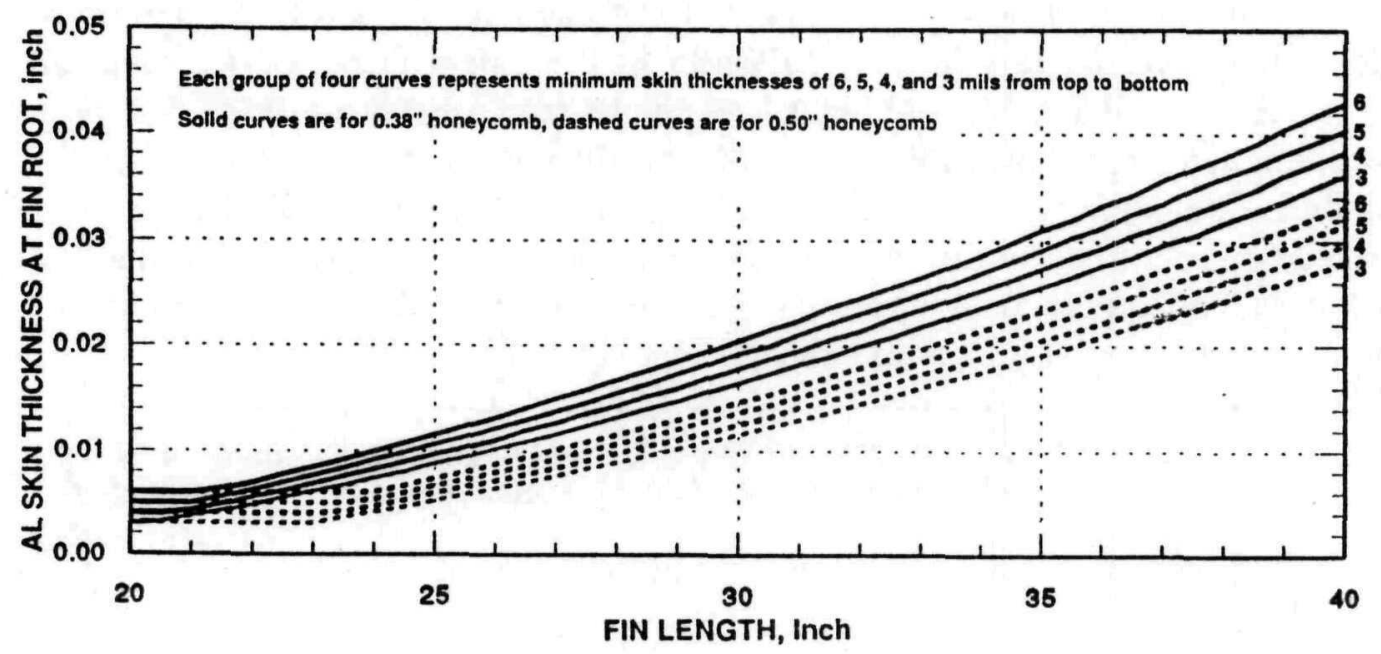

FIGURE 12. Effect of Fin Length and Honeycomb Thickness on Required Aluminum Skin Thickness at Fin Root.

As shown above, increasing the honeycomb thickness reduces the required skin thickness. But Figure 13 shows that the resultant mass saving is less than the additional honeycomb mass. Consequently, the total radiator mass is somewhat lower for the 0.38 " honeycomb than for the 0.50 " thickness, and that thickness was adopted in our subsequent designs.

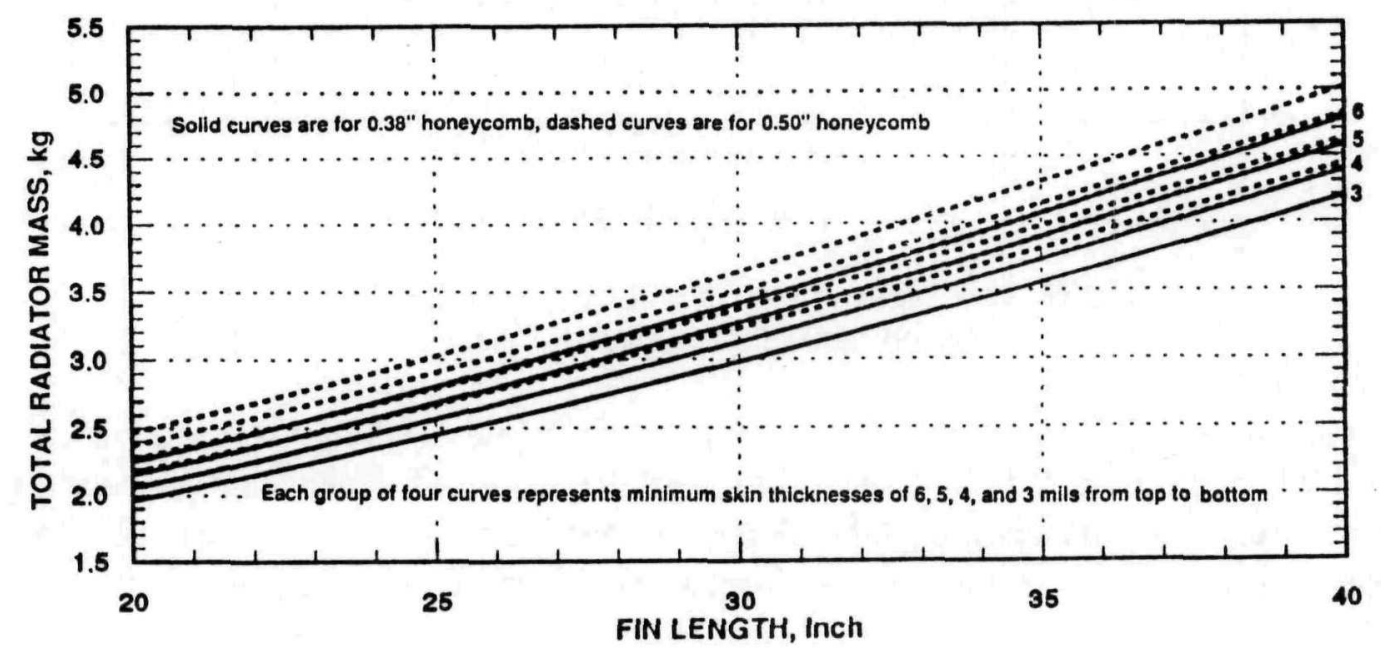

FIGURE 13. Effect of Fin Length and Honeycomb Thickness on Total Radiator Mass.

The preceding quasi-static analysis was supplemented by a dynamic analysis using a detailed NASTRAN [6] model of the radiator fin consisting of 966 nodes and 1717 elements. A plate element mesh was used for each of the two aluminum face sheets and for the two graphitized carbon-carbon sheets. The honeycomb core was modeled with four layers of solid elements, and the heat pipe walls were 
represented by plate elements. Since the graphitized carbon-carbon material is highly anisotropic, orthotropic material properties were used in the NASTRAN model. The honeycomb core is also orthotropic and was assumed to have its higher shear strength L-direction (ribbon direction) oriented in the long fin direction, and its W-direction (transverse to the ribbon) parallel to the vertical axis.

Modal analyses followed by random analyses were conducted on several fin configurations of interest. The results were reassuring for the smaller fin sizes, but as the fin areas increased, so did concern about the possible acoustic response of the large, light structures. To address this, an acoustic analysis of one of the larger fin sizes (30" length by 20 " tip height with a $0.5^{\prime \prime}$ honeycomb) was conducted using the VAPEPS (VibroAcoustic Payload Environment Prediction System) computer code [7]. The results for an STS launch vehicle and a tenminute acoustic loading yielded an acoustic response of 184,000 stress reversal cycles. For 6061-T6 aluminum, Miner's cumulative fatigue damage index [8] yielded a safety margin of $69 \%$.

\section{Parametric System Analysis and Optimization}

Let us first examine the effect of varying the graphite skin thickness on system characteristics for a set of illustrative parameters. For a 30 " root-to-tip fin length, a 20 " tip height, a 0.38 " honeycomb thickness, a 0.003 " aluminum skin thickness, and a converter with $90 \%$ active cell area, the effect of varying the graphite skin thickness from 0 to 0.030 " is illustrated in Figure 14. The figure shows the effect of graphite skin thickness on system mass, cell temperature, output power, system efficiency, and specific power. In each of the three figures, the solid curve represents results based on measured values of filter transmittance and cell quantum efficiency, and the dashed curve is based on the projected values listed in Table I.

As shown in Figure 14, the projected properties (primarily the filter transmittance) have a pronounced effect on system performance. It is also noteworthy that initially the addition of the graphite skins benefits output power and efficiency significantly, but after adding a surprisingly small thickness (typically 0.005 ") further additions of graphite only increase the mass with little further increase of power or efficiency.

Similar analyses were carried out for fin lengths ranging from 20 " to $40^{\prime \prime}$ and for fin tip heights of 12 " and 20". The results for all cases showed similar trends, confirming the previous conclusion that the specific power of the design is maximized at a graphite skin thickness around $0.005 "$. With thicker graphite skin, 


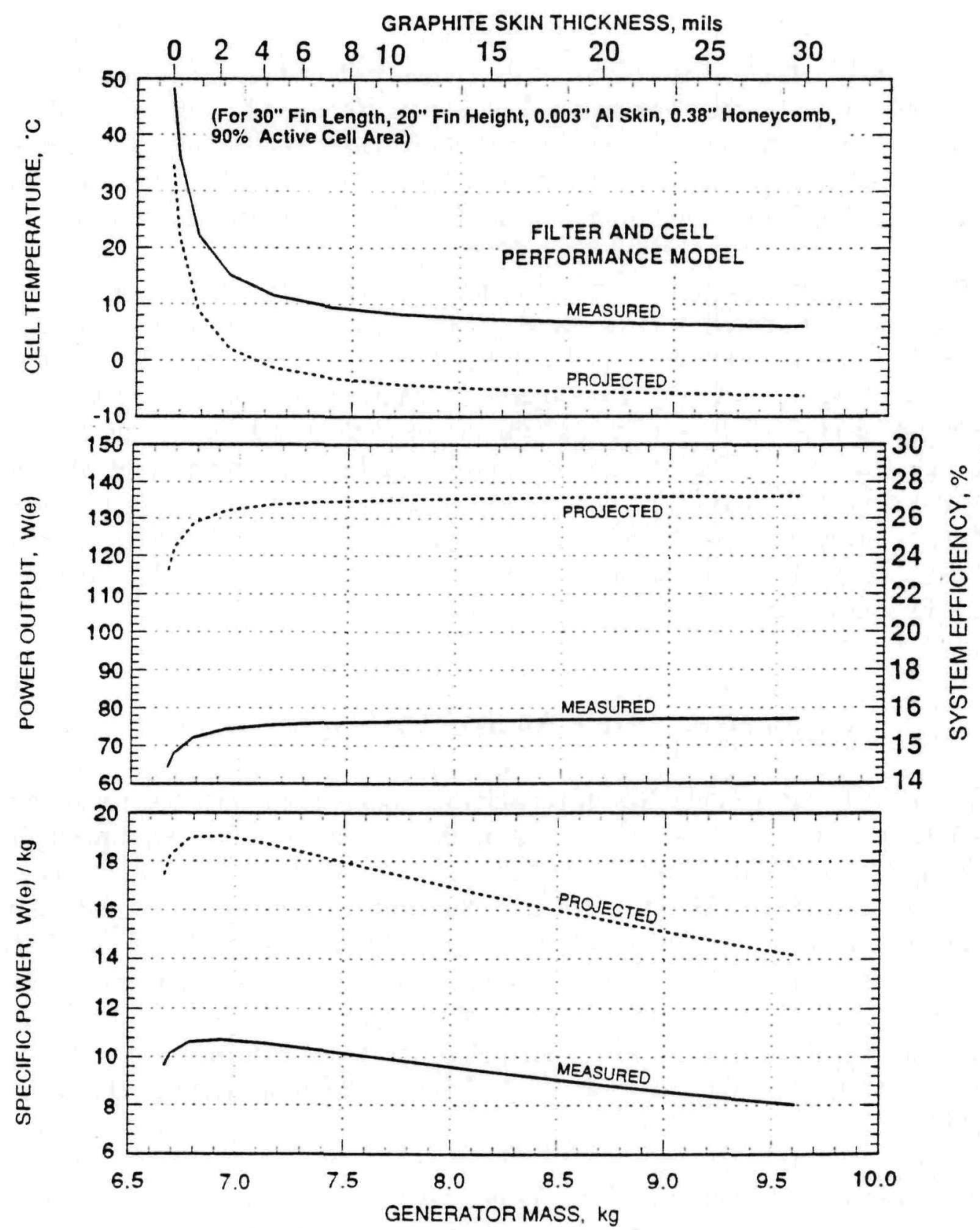

FIGURE 14. Effect of Graphite Skin Thickness.

the increase in power output is quite small and is outweighed by the increased graphite mass.

The results of the parametric design studies are displayed in Figure 15 and 16. Both figures show curves representing the results of thermal, electrical, and mass analyses for fin lengths ranging $20^{\prime \prime}$ to $40^{\prime \prime}$ and fin tip heights ranging from 12 " to 20 ", with the graphite skin thickness as the implicit variable within each curve. 
Each point on each curve is the result of an iterative solution of the coupled thermal and electrical analyses, using the modified thermal analysis code described earlier. All curves assume aluminum skins varying from 0.003 " at the fin tip to whatever is needed near the fin root to survive a 40-g launch load without exceeding the $23 \mathrm{ksi}$ allowable stress limit.

Figure 15 shows plots of cell temperature versus generator mass. For each fin size, the upper curve is based on the measured filter transmittance and PV quantum efficiency model, and the lower curve is for the projected improved filter and cell characteristics. As can be seen, the larger fins lead to very low cell temperatures, but at substantially higher masses.

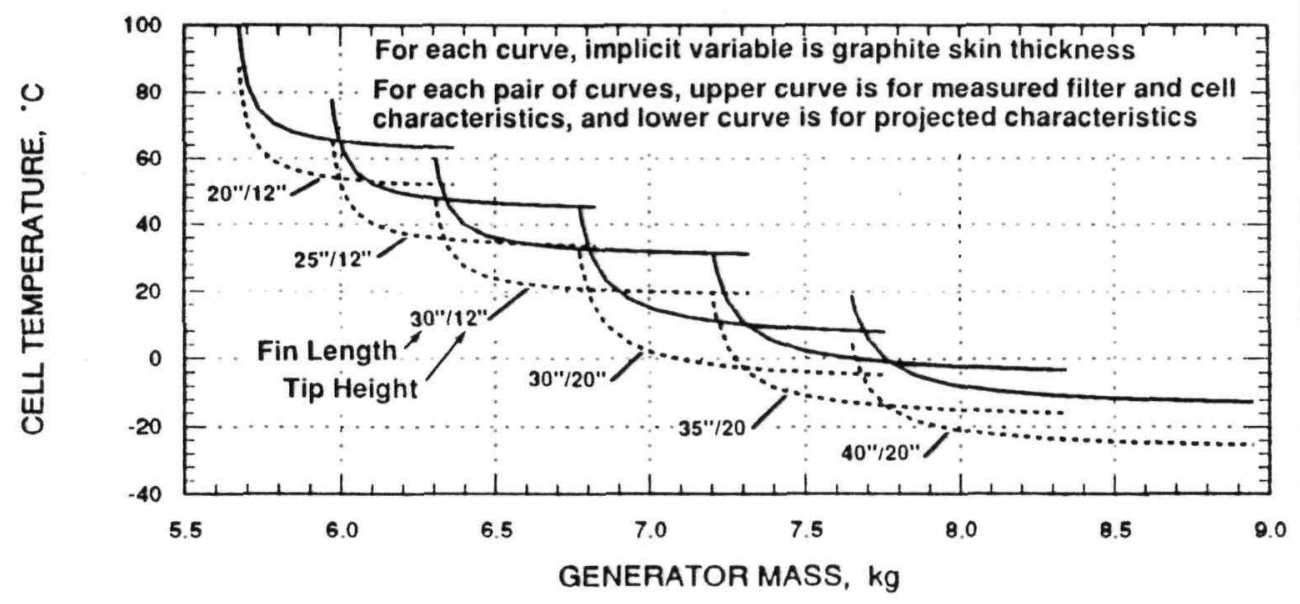

FIGURE 15. Effect of Fin Dimensions on Cell Temperature.

The trade-offs between mass and performance are summarized in Figure 16. For each fin size, it presents a curve of output power and system efficiency versus generator mass, with graphite skin thickness as the implicit variable. It also shows diagonal lines of constant specific power, which identify the fin dimensions that maximize the generator's specific power.

For the measured and projected filter and cell performance models, the figure shows a dashed envelope curve tangent to each family of performance curves for different fin dimensions. For each performance model, the corresponding envelope curve represents the highest specific power that can be achieved by optimizing the system's radiator geometry. For every point on the envelope, there is some combination of fin length, fin tip height, and graphite skin thickness that will achieve the indicated performance.

As can be seen, for both performance models the system's specific power is maximized with a 30 " fin length and 20 " fin height. But note that this optimum is quite broad. As illustrated in Table 2, major deviations from the optimum design 


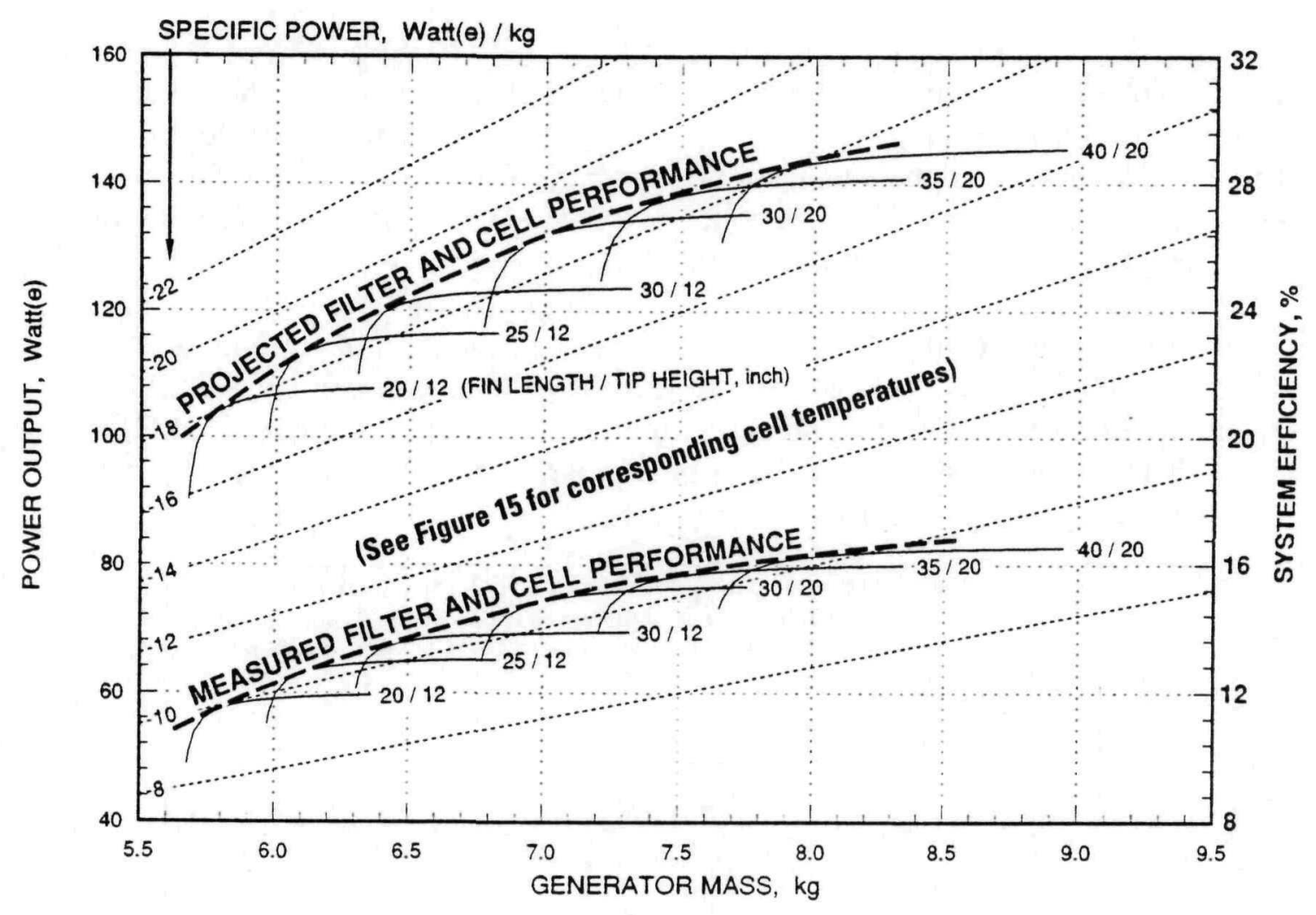

FIGURE 16. BOM Power, System Efficiency, and Specific Power Versus Generator Mass (and Implicit Graphite Thickness).

result in only modest reductions in specific power. Thus, the designer has wide latitude in trading off power versus mass to meet specific mission goals. For example, for the projected filter and cell performance, the BOM power could be raised from 130 watts to 145 watts by lengthening the fins from 30 " to 40". As shown, this would increase the generator's mass from 7.2 to $8.2 \mathrm{~kg}$, but would only decrease its specific power from 18.6 to $17.6 \mathrm{w} / \mathrm{kg}$. Conversely, if desired the generator mass could be reduced from $7.2 \mathrm{~kg}$ to $5.7 \mathrm{~kg}$ by reducing the fin size. As shown, this would reduce the BOM power from 130 watts to 103 watts, but would only lower the generator's specific power from 18.6 to $18.0 \mathrm{w} / \mathrm{kg}$.

TABLE 2: Effect of Off-Optimum Design on RTPV Performance

\begin{tabular}{lccc}
\hline \multicolumn{1}{c}{ Goal } & Low Mass & Max Sp Power & High Power \\
\hline Fin Length & $20^{\prime \prime}$ & $30^{\prime \prime}$ & $40^{\prime \prime}$ \\
Fin Tip Height & $12^{\prime \prime}$ & $20^{\prime \prime}$ & $20^{\prime \prime}$ \\
Cell Temperature & $68^{\circ} \mathrm{C}$ & $0^{\circ} \mathrm{C}$ & $-21^{\circ} \mathrm{C}$ \\
Power (BOM) & $103 \mathrm{w}$ & $130 \mathrm{w}$ & $145 \mathrm{w}$ \\
Efficiency (BOM) & $20.6 \%$ & $26.0 \%$ & $29.0 \%$ \\
System Mass & $5.7 \mathrm{~kg}$ & $7.2 \mathrm{~kg}$ & $8.2 \mathrm{~kg}$ \\
Specific Power & $18.0 \mathrm{~W} / \mathrm{kg}$ & $18.6 \mathrm{w} / \mathrm{kg}$ & $17.6 \mathrm{~W} / \mathrm{kg}$ \\
\hline
\end{tabular}


The optimum 30" fin length and 20" fin tip height were used in the RTPV design illustrations shown in the preceding paper [1]. For those dimensions, Table 3 presents a detailed mass breakdown, and Table 4 lists key parameters of the RTPV system for both the measured and the projected models of filter transmittance and cell quantum efficiency. For comparative purposes, the tables also list the same parameters for a recently designed RTG [9] for the Pluto Fast Flyby mission:

TABLE 3. Comparative Mass Breakdown (kg)

\begin{tabular}{lcc}
\hline Generator & RTG & RTPV \\
\hline GPHS Modules & & \\
Fuel (PuO2) & 2.98 & 1.19 \\
Clads (Ir) & 1.17 & 0.47 \\
Graphitics & 3.09 & 1.23 \\
Canister (Mo) & 0.00 & 0.63 \\
Structural Supports & 1.07 & 0.00 \\
Multifoil Insulation (Mo) & 1.44 & 0.09 \\
Converter Elements, etc. & 2.15 & 0.17 \\
Housing, etc. & 2.90 & 0.53 \\
Radiator & 1.56 & 2.85 \\
TOTAL & 15.36 & 7.16 \\
\hline
\end{tabular}

As shown, the optimum radiator mass is only $10 \%$ of the RTG mass but $40 \%$ of the RTPV mass. This confirms the importance of optimizing the RTPV's radiator design. The RTPV design - for both the measured and the projected performance models - offers very substantial mass improvements over the RTG. Its mass is less than half the RTG mass. It not only meets JPL's very ambitious mass reduction goal of $9.5 \mathrm{~kg}$, but at $7.2 \mathrm{~kg}$ it greatly exceeds it. The requirements for the costly radioisotope fuel capsules is reduced by $60 \%$, which can result in substantial cost reductions, since historically the fuel capsules and its graphitic enclosures are the dominant cost components of RTGs.

For both the Measured and Projected filter and cell performance models, Table 4 compares the BOM operating temperatures and system characteristics of the RTPV with those of the RTG, and shows the effect of 9-year fuel decay on the RTPV's performance.

The computed $1128^{\circ} \mathrm{C} \mathrm{BOM}$ aeroshell temperature for the projected filter and cell performance is somewhat above the corresponding $1100^{\circ} \mathrm{C}$ temperature in RTGs. But this does not matter, because the critical temperature is not the aeroshell's but the clad's. Excessive clad temperatures can result in grain growth and embrittlement of the iridium alloy, which can lead to clad breach in case of inadvertent earth impact. The computed RTPV clad temperature of $1210^{\circ} \mathrm{C}$ is well below the $1300^{\circ} \mathrm{C}$ clad temperature in previous RTGs. This is because the 
TABLE 4. RTG/RTPV BOM Performance Comparison and Effect of 9-year Fuel Decay

\begin{tabular}{lccccc}
\hline \multicolumn{1}{c}{ Generator } & RTG & \multicolumn{3}{c}{ RTPV } \\
\hline Mission Phase & BOM & \multicolumn{3}{c}{ BOM } & \multicolumn{3}{c}{ EOM $^{*}$} \\
\hline Performance Model & Unicouple & Measured & Projected & Measured & Projected \\
\hline Generator Mass, kg & 15.4 & 7.2 & 7.2 & 7.2 & 7.2 \\
Number of H.S. Modules & 5 & 2 & 2 & 2 & 2 \\
Thermal Power, watts & 1250 & 500 & 500 & 465 & 465 \\
Operating Temps, ${ }^{\circ} \mathrm{C}:$ & & & & & \\
$\quad$ Clad & 1326 & 1153 & 1210 & 1132 & 1190 \\
Aeroshell & 1060 & 1062 & 1128 & 1045 & 1111 \\
Canister & none & 1034 & 1103 & 1018 & 1087 \\
Converter & $990 / 267$ & 11 & -2 & -4 & -8 \\
Radiator Heatpipe & none & -9 & -19 & -14 & -24 \\
Output Voltage & 19 & 26.5 & 28.6 & 26.7 & 28.6 \\
Output Current, amps & 4.6 & 2.9 & 4.7 & 2.6 & 4.4 \\
Output Power, watts & 87 & 76 & 134 & 71 & 126 \\
System Efficiency, \% & 7.0 & 15.1 & 26.8 & 15.2 & 27.1 \\
Specific Power, watts/kg & 5.7 & 10.4 & 18.5 & 9.7 & 17.4 \\
\hline
\end{tabular}

* Effect of fuel decay only, before correcting for radiation effects.

presence of helium within the RTPV canister reduces the normal temperature drops between the clad and the aeroshell. In addition, a separate analysis showed that loss of helium from the canister would only result in a clad temperature rise to $1305^{\circ} \mathrm{C}$, which is still within the prescribed clad temperature limit of $1330^{\circ} \mathrm{C}$. This is important, because it means that the reliability and safety of the RTPV are not dependent on retaining the hermeticity of the canister.

Comparison of the BOM and EOM columns shows that 9-year fuel decay drops the canister temperature by $16^{\circ} \mathrm{C}$ and the cell temperature by $6^{\circ} \mathrm{C}$. This reduces the output power and specific power by $6 \%$, but raises the system efficiency by $1 \%$.

Table 4 further shows that replacement of the RTG with an RTPV having Boeing's projected filter and cell performance would roughly quadruple the generator's efficiency and triple its specific power. Moreover, it's BOM power output of 134 watts would result in an EOM output greatly in excess of JPL's 70watt goal. This excess power capability would not be wasted, since it could be used for faster post-encounter data transmission to Earth, which would significantly reduce the mission's operating costs. Alternatively, the system mass could be reduced to $5.7 \mathrm{~kg}$ through use of smaller fins, which would still leave a BOM output of 103 watts. 


\section{PROGRAMMATIC CONCLUSIONS}

In spite of the RTPV system's potential performance superiority, the PFF project at present is likely to select the existing RTG technology because its technical maturity is much greater than that of the TPV system. There have been some successful tests of gallium antimonide cells, with and without filters, but these used unoptimized cells made for the solar power program that did not reflect the full potential of the TPV converters.

Recently, Boeing conducted a preliminary scaled-down test for JPL's PFF project that endeavored to simulate the RTPV system [10]. While they reported encouraging results $\left(13.3 \%\right.$ measured efficiency at $\left.1010^{\circ} \mathrm{C}\right)$, the test was hampered by constrained funding $(\$ 250 \mathrm{~K})$ and time limits (6 months). These limits did not permit construction and optimization of new cells and filters, and forced the use of components left over from previous programs. Those components were not only unoptimized, but the cells used came from different production batches that did not even match each other's performance, partly because of differences in contact metallization. Also, the anti-reflection coatings used were not optimized for the RTPV application. In addition, the number of available components was too small to cover more than a small fraction of the simulated heat source's surface area. Because of these limitations, the test results - while encouraging - were far from demonstrating the full potential of the RTPV system.

A concerted development effort could fairly quickly determine whether the above short-comings could, in fact, be corrected and result in the predicted BOM performance improvements. A prudent demonstration program should consist of a sequence of three steps, with each step initiated after successful demonstration of the preceding one. The first step would be a component development effort to determine whether Boeing's projected filter transmittance and cell reflectance, together with improved anti-reflection coatings and cell contacts, can in fact be realized. The second step would be to perform additional analyses and tests to confirm that radiation-induced degradation is of acceptable magnitude. If so, the third step would be construction of a full-scale prototypic converter array with an electrically heated $\mathrm{Mo} / \mathrm{W}$ canister and a water-cooled housing, and tests to demonstrate that its BOM performance matches analytical predictions.

But even if that is successfully completed, could technology-readiness for a nine-year flight mission be demonstrated in time for the PFF program? Ordinarily, such a demonstration is a very time-consuming process, because of the need for the lengthy life tests to demonstrate reliability and performance stability. However, there are several aspects of the RTPV design that may greatly reduce the need for lengthy tests: 
- The heat source employs standard GPHS modules that have already been developed, safety-tested, life-tested, and successfully used in RTGs on previous flight programs. Therefore, the costly safety tests need not be repeated as long as the launch vehicle is no more severe than the previously used Shuttle and Titan-4.

- The GPHS modules are completely enclosed in a canister, to prevent access of sublimates and outgassing products to the PV cells.

- The canister is coated with tungsten to minimize sublimation. At $1100^{\circ} \mathrm{C}$, tungsten sublimation is only $10^{-6}$ atomic monolayers in ten years.

- The filters employ gold, which is stable at the cold converter temperature. There is no need to develop exotic new materials with unknown degradation effects. The projected filter improvements require geometric rather than chemical modifications.

- The TPV cells and arrays are derivatives of solar system PV arrays and can benefit from fabrication methods developed for those systems over many years.

- The alpha particles emitted by the fuel are completely stopped by the canister. Neutron and gamma emission are orders of magnitude less than from reactors, and their effect on PV cells can be measured quickly by accelerated tests.

- Most important, the lengthy tests usually required to determine temperatureinduced degradation effects are not needed, because RTPV cells operate cold $\left(0-10^{\circ} \mathrm{C}\right)$.

The above factors may minimize the need for long-term testing and make it possible to establish the RTPV system's flight readiness within the required PFF schedule, if their development is initiated soon. In any event, it is clear that the very substantial improvements in system efficiency and specific power that would result from successful development of radioisotope thermophotovoltaic generators by DOE and/or NASA would make such systems of great value not only for the Pluto Fast Flyby mission but also for other missions requiring small, long-lived, low-mass generators in the future.

\section{ACKNOWLEDGMENTS}

The author takes pleasure in acknowledging the contributions of $\mathrm{E}$. Horne and M. Morgan of the Boeing Company in providing the theoretical guidance and 
experimental data which formed the essential foundation of the present study. He also acknowledges the encouragement and support provided by A. Newhouse, Director of the Department of Energy's Space and Defense Power Systems Office, and of R. Lange, Director of its Radioisotope Power Systems Division; and appreciates the interest displayed by JPL's PFF Project Team led by R. Staehle.

\section{REFERENCES}

1. Schock, A., and V. Kumar, "Radioisotope Thermophotovoltaic System Design and its Application to an Illustrative Space Mission," Proceedings of the NREL Conference on Thermophotovoltaic Generation of Electricity, held at Copper Mountain, CO, July 1994, published by the American Institute of Physics.

2. Touloukian, Y.S. and D.P. Devitt, Thermophysical Properties of Matter, Vol 7; Thermal Radiative Properties, Metallic Elements and Alloys, 1970.

3. Gaski, J., SINDA (System Improved Numerical Differencing Analyzed), version 1.315 from Network Analysis Associate, Fountain Valley, CA, 1987.

4. Little, A.D., SSPTA (Simplified Space Payload Thermal Analyzer), version 3.0/VAX, by Arthur D. Little Inc., for NASA/Goddard, by Arthur D. Little Inc., Cambridge, MA, 1986.

5. Schock, A. and H. Sookiazian, "Design Optimization of RTG for Solar-Polar Mission," \#799307 in Proc. of 14th Intersociety Energy Conversion Engineering Conference, held in Boston, MA, 1979.

6. MSC/NASTRAN, Versions 65 thru 67.5. Based on NASA's NASTRAN general purpose structural analysis program. Developed and maintained by McNeal-Schwindler Corporation (MSC), CA.

7. VibroAcoustic Payload Environment Prediction Systems (VAPEPS). Database maintained at the VAPEPS Management Center, JPL, Pasadena, CA.

8. Miner, M.A., "Cumulative Damage in Fatigue," J. Appl. Mech., 12, September 1945.

9. Schock, A., "RTG Options for Pluto Fast Flyby Mission," IAF-93-R.1.425a, presented at the 44th Congress of the International Astronautical Federation, Graz, Austria, 16-22 October 1993.

10. Boeing Defense and Space Group, "Thermophotovoltaic Thermal-to-Electric Conversion Systems Report," Final Report to JPL on Contract 959595, December 20, 1993. 